\title{
Low-temperature infrared spectrum and atomic-scale structure of hydrous defects in diopside
}

\author{
Etienne Balan ${ }^{1}$, Lorenzo Paulatto ${ }^{1}$, Jia Liu ${ }^{2,3}$, and Jannick Ingrin ${ }^{2,3}$ \\ ${ }^{1}$ Sorbonne Université, CNRS, MNHN, Institut de Minéralogie, de Physique des Matériaux et de Cosmochimie \\ (IMPMC), 4 place Jussieu, 75252 Paris CEDEX 05, France \\ ${ }^{2}$ Univ. Lille, CNRS, INRAE, ENSCL, UMR 8207 - UMET - Unité Matériaux et Transformations, \\ 59000 Lille, France \\ ${ }^{3}$ School of Earth Sciences, Zhejiang University, Hangzhou, 310027, China
}

Correspondence: Etienne Balan (etienne.balan@sorbonne-universite.fr)

Received: 24 May 2020 - Revised: 18 September 2020 - Accepted: 29 September 2020 - Published: 14 October 2020

\begin{abstract}
Hydrous defects in diopside $\left(\mathrm{CaMgSi}_{2} \mathrm{O}_{6}\right)$ play an important role in the water budget of the Earth's mantle. Related $\mathrm{OH}$-stretching modes lead to a variety of infrared absorption bands observed in natural or experimental samples. In the present study, we report new low-temperature infrared spectra of reference natural diopside samples in the OH-stretching range. In parallel, the structure and vibrational properties of a series of $\mathrm{OH}$-bearing defects in diopside are theoretically determined at the density functional theory level. The infrared spectra make it possible to resolve additional bands in the region above $3600 \mathrm{~cm}^{-1}$ and reveal that their anharmonic behavior differs from that of the bands at lower frequency. A comparison of theoretical results with experimental data makes it possible to propose atomic-scale geometries corresponding to observed $\mathrm{OH}$-stretching bands. It confirms that the bands observed at $3620-3651 \mathrm{~cm}^{-1}$ are related to $\mathrm{M}^{3+}$ ions substituted for $\mathrm{Si}$ in tetrahedral sites, while the $3420 \mathrm{~cm}^{-1}$ band is associated with the $\mathrm{Na}^{+}$for $\mathrm{Ca}^{2+}$ substitution. In both cases, $\mathrm{H}^{+}$incorporation compensates the charge deficit due to the heterovalent substitution. The other major mechanism of water incorporation in diopside relates to the charge compensation of cationic vacancies, among which $\mathrm{Ca}$ vacancies play a central role. The $3357 \mathrm{~cm}^{-1}$ band corresponds to doubly protonated $\mathrm{Ca}$ vacancies in pure diopside. In experimental diopside-bearing trivalent cations, the bands at $3432-3460 \mathrm{~cm}^{-1}$ correspond to singly protonated Ca vacancies with a nearby octahedral $\mathrm{M}^{3+}$ ion, while the $3310 \mathrm{~cm}^{-1}$ band likely involves a more remote charge compensation by $\mathrm{M}^{3+}$ ions. More complex defects associating Ca vacancies with tetrahedral $\mathrm{M}^{3+}$ and octahedral $\mathrm{Ti}^{4+}$ ions are proposed for the bands observed between 3500 and $3600 \mathrm{~cm}^{-1}$ in natural diopside. The $\mathrm{Fe}^{2+}$ for $\mathrm{Mg}^{2+}$ and $\mathrm{Fe}^{2+}$ for $\mathrm{Ca}^{2+}$ substitutions are also found to affect nearby $\mathrm{OH}$-bearing defects, causing a shift and broadening of $\mathrm{OH}$ stretching bands in chemically more complex diopside samples.
\end{abstract}

\section{Introduction}

Diopside is considered a major host of "water" in the upper mantle (e.g., Demouchy and Bolfan-Casanova, 2016) contributing to the Earth global budget of water. As in other nominally anhydrous minerals, water occurs as hydroxyl groups associated with cationic vacancies or chemical impurities, ensuring the electric neutrality of the defective crystal (e.g., Keppler and Smyth, 2006; Skogby, 2006). The occurrence of $\mathrm{OH}$ groups at low concentration in natural and experimental samples of diopside is attested by their characteristic $\mathrm{OH}$ stretching bands in Fourier-transform infrared (FTIR) spectra. Various bands differing in position and pleochroism have been identified and categorized. In pure diopside, the spectra display a prominent band observed at $3357 \mathrm{~cm}^{-1}$ and ascribed to divalent cation vacancies compensated by two protons (Stalder and Ludwig, 2007; Sundvall et al., 2009; Purwin et al., 2009). At variance, natural samples, as well as experimental samples doped with chemical impurities, display a larger variety of signals. The spectra of diopside, containing trivalent cations and synthesized at $20 \mathrm{kbar}$ under silica 
saturation, display two additional bands, one at $3310 \mathrm{~cm}^{-1}$ and the other one observed between 3432 and $3462 \mathrm{~cm}^{-1}$ depending on the nature of the trivalent impurity (Stalder and Ludwig, 2007). Band absorbances generally follow the or$\operatorname{der} E / / \gamma \gg E / / \beta \cong E / / \alpha$, where $\alpha, \beta$ and $\gamma$ correspond to the principal axes of the optic indicatrix and $E$ denotes the polarization of the infrared beam. Under the same conditions, sodium-bearing samples display a band at $3428 \mathrm{~cm}^{-1}$ with the absorbance order $E / / \beta \cong E / / \alpha \gg E / / \gamma$ (Purwin et al., 2009). Al-bearing synthetic samples can also display an absorption band at $3650 \mathrm{~cm}^{-1}$, as well as a doublet at $\sim 3450$ and $\sim 3500 \mathrm{~cm}^{-1}$, depending on the synthesis conditions (Gavrilenko et al., 2010). Absorption bands above $3600 \mathrm{~cm}^{-1}$ have been reported in experimental Fe-bearing samples (Skogby, 1994) and natural samples (Ingrin et al., 1989; Johnson et al., 2002; Andrut et al., 2007). Their absorbance follows the order $E / / \beta>E / / \alpha \gg E / / \gamma$, and they are usually ascribed to the coupled incorporation of trivalent cations and protons at the tetrahedral Si site (e.g., Beran, 1976; Skogby et al., 1990; Johnson et al., 2002; Bromiley et al., 2004; Gavrilenko et al., 2010). In natural samples, the origin of several bands observed between 3500 and $3600 \mathrm{~cm}^{-1}$ is still debated (e.g., Yang et al., 2019; Azevedo-Vannson et al., 2020). These bands are prominent in uncommon spectra of upper-mantle xenoliths (Denis et al., 2015; Patkó et al., 2019; Azevedo-Vannson et al., 2020).

In the present study, we report new low-temperature infrared spectra of natural diopside samples previously investigated by Ingrin et al. (1989), Andrut et al. (2007), and Yang et al. (2019). In parallel, we use a quantum-mechanical modeling approach to investigate the structure and infrared spectroscopic properties of a series of OH-bearing defects in diopside. This approach has been previously used to interpret the infrared spectrum of $\mathrm{OH}$ defects in important silicate-group minerals (e.g., Wright, 2006; Balan et al., 2011, 2013, 2017; Blanchard et al., 2009, 2017; Ingrin et al., 2014; Jollands et al., 2020). Combining experimental observations and theoretical results provides important constraints to help unravel the atomic-scale structure of $\mathrm{OH}$ defects in diopside.

\section{Methods}

\subsection{Low-temperature infrared spectroscopy}

The samples are well-characterized gem-quality diopside crystals from Austria and Russia previously investigated by Ingrin et al. (1989), Andrut et al. (2007), and Yang et al. (2019). Their composition is close to the endmember composition: $\mathrm{Ca}_{0.97} \mathrm{Cr}_{0.01} \mathrm{Mg}_{0.97} \mathrm{Fe}_{0.04} \mathrm{Al}_{0.01} \mathrm{Si}_{1.99} \mathrm{O}_{6}$ and $\mathrm{Ca}_{0.99} \mathrm{Mn}_{0.01} \mathrm{Mg}_{0.94} \mathrm{Fe}_{0.06} \mathrm{Al}_{0.01} \mathrm{Si}_{1.99} \mathrm{O}_{6}$ for the Russian and Austrian samples, respectively. For the Russian sample, infrared transmission spectra have been recorded at a $2 \mathrm{~cm}^{-1}$ resolution with 128 scans accumulated per spectrum using a cryogenic cell cooled with a liquid helium sys- tem and a Brucker FTS-IFS 66v spectrometer from Institut d'Astrophysique Spatiale (IAS), Orsay, France. For this analysis, unpolarized measurements were performed on two pieces of the same slice of the Russian diopside. One piece was heated in air at $1000^{\circ} \mathrm{C}$ for $320 \mathrm{~h}$ in order to remove all hydrogen present in the sample and was used to build reference spectra collected at the different temperatures. The reported spectra were then collected on the second untreated piece using the reference spectrum for background correction. For the Austrian sample, the spectra have been recorded at a resolution of $2 \mathrm{~cm}^{-1}$ with 150 scans accumulated per spectrum using a Perkin Elmer GX2000 spectrometer. The temperature was monitored using a Linkam FTIR600 stage cooled with liquid nitrogen with $\mathrm{ZnSe}$ windows dedicated to infrared measurements, and the background was measured for each temperature through the cooling stage (Ingrin et al., 2013). A polynomial baseline was subtracted from the spectrum.

\subsection{Theoretical modeling of $\mathrm{OH}$ defects}

The properties of $\mathrm{OH}$ defects have been theoretically investigated within the density functional theory (DFT) framework using the PWscf code of the Quantum ESPRESSO package (Giannozzi et al., 2009; http://www.quantum-espresso.org, last access: 1 October 2020). The modeling scheme used the generalized gradient approximation (GGA) to the exchangecorrelation functional as proposed by Perdew, Burke and Ernzerhof (PBE functional; Perdew et al., 1996), and periodic boundary conditions. The ionic cores were described using optimized norm-conserving Vanderbilt (ONCV) pseudopotentials (Hamann, 2013; Schlipf and Gygi, 2015) with a 80 Ry cutoff on the electronic wave functions, as in Balan et al. (2019) and Jollands et al. (2020). Structural properties of $\mathrm{OH}$-bearing defects were determined using $1 \times 1 \times 2$ diopside supercells (80 atoms) containing up to four hydrogen atoms. Brillouin zone sampling for the electronic integration was restricted to the $\Gamma$ point. Unit-cell parameters of pure diopside (monoclinic, S.G. C2/c) were optimized at zero pressure $\left(a=9.88 \AA, b=9.02 \AA, c=5.33 \AA, \beta=106.5^{\circ}\right)$ and were used without further relaxation to produce the $\mathrm{OH}$-bearing supercells. As usually observed in DFT modeling of silicates performed at the GGA level, the theoretical cell lengths are overestimated with respect to those determined experimentally $\left(a=9.745 \AA, b=8.899 \AA, c=5.251 \AA, \beta=105.63^{\circ}\right.$; Cameron et al., 1973). For all systems, the relaxation of atomic internal coordinates was performed until the residual forces were less than $10^{-4}$ Ry a.u. $^{-1}$. For models containing isolated paramagnetic cations $\left(\mathrm{Ti}^{3+}, \mathrm{Cr}^{3+}, \mathrm{Fe}^{3+}, \mathrm{Fe}^{2+}\right)$, spin-polarized calculations have been performed imposing the high-spin state of the ion to the supercell.

The vibrational modes, the Born effective charge tensors and the electronic dielectric tensor were calculated at the Brillouin zone center $(\Gamma$ point) using the linear response theory (Baroni et al., 2001) as implemented in the PHonon code 
(Giannozzi et al., 2009; http://www.quantum-espresso.org; last access: 1 October 2020). The high-frequency OH stretching modes that are decoupled from the other vibrational modes occurring at a significantly lower frequency can be accurately calculated by only considering the displacement of the oxygen and hydrogen atoms involved in $\mathrm{OH}$ groups (Balan et al., 2008). The complex low-frequency dielectric permittivity tensor has been calculated for each defect by adding only the ionic contributions related to the $\mathrm{OH}$ stretching modes to the electronic permittivity tensor and using an arbitrary damping parameter of $4 \mathrm{~cm}^{-1}$, accounting for the width of absorption bands (Balan et al., 2008). For a symmetry lower than orthorhombic, the orientation of the principal axes of the dielectric tensor of the pristine or defective crystal is not fully constrained by the crystal symmetry. The principal axes of the index and absorption tensors may thus differ, which complicates the straightforward computation of the infrared absorption spectrum (e.g., Sambridge et al., 2008). To circumvent this difficulty, the anisotropy of the electronic contribution to the dielectric tensor was neglected as this anisotropy marginally affects the value of the absorption coefficient. Infrared absorption coefficients were then computed for polarizations parallel to the axes of an orthogonal frame $(u \alpha, u \beta$, and $u \gamma)$ chosen such that it approximately coincides with the experimentally determined principal axes of diopside optic indicatrix (e.g., Hess, 1949). The $u \beta$ orientation is parallel to the crystal $b$ axis, and $u \gamma$ forms an angle of $40^{\circ}$ with the $c$ axis and $u \alpha$ an angle of $23.5^{\circ}$ with the $a$ axis. In the following, $u \alpha, u \beta$ and $u \gamma$ refer to the theoretical axes, while $\alpha, \beta$ and $\gamma$ refer to the experimental geometry.

\section{Results}

\subsection{Low-temperature infrared spectra of diopside}

The infrared spectra of reference diopside samples (Fig. 1) display a series of well-resolved $\mathrm{OH}$-stretching bands characteristic of $\mathrm{OH}$ defects in diopside (e.g., Ingrin et al., 1989; Andrut et al., 2003, 2007; Yang et al., 2019). An asymmetric band at $3646-3650 \mathrm{~cm}^{-1}$ with a shoulder at $\sim 3611 \mathrm{~cm}^{-1}$ is observed at near-ambient temperature in both samples. Two bands at 3528 and $3550 \mathrm{~cm}^{-1}$ significantly contribute to the spectrum of the Russian sample, while their relative intensity is weaker in the Austrian sample. In contrast, the Austrian sample displays two additional bands at 3466 and $3358 \mathrm{~cm}^{-1}$. The low-temperature spectra reveal that the behavior of bands above $3600 \mathrm{~cm}^{-1}$ differs from that of the bands observed at lower frequency, although a narrowing is observed for all the bands. Moderate shifts are observed for the bands toward $3358\left(-3 \mathrm{~cm}^{-1}\right), 3466\left(<1 \mathrm{~cm}^{-1}\right)$, $3528\left(<1 \mathrm{~cm}^{-1}\right)$ and $3550 \mathrm{~cm}^{-1}\left(+7 \mathrm{~cm}^{-1}\right)$. In contrast, the band at $3646-3650 \mathrm{~cm}^{-1}$ shifts to $3663 \mathrm{~cm}^{-1}$, i.e., by $+13-$ $17 \mathrm{~cm}^{-1}$, corresponding to a slope of $\sim 0.07 \mathrm{~cm}^{-1} \mathrm{~K}^{-1}$. The shoulder at $\sim 3611 \mathrm{~cm}^{-1}$ leads to a well-resolved band at

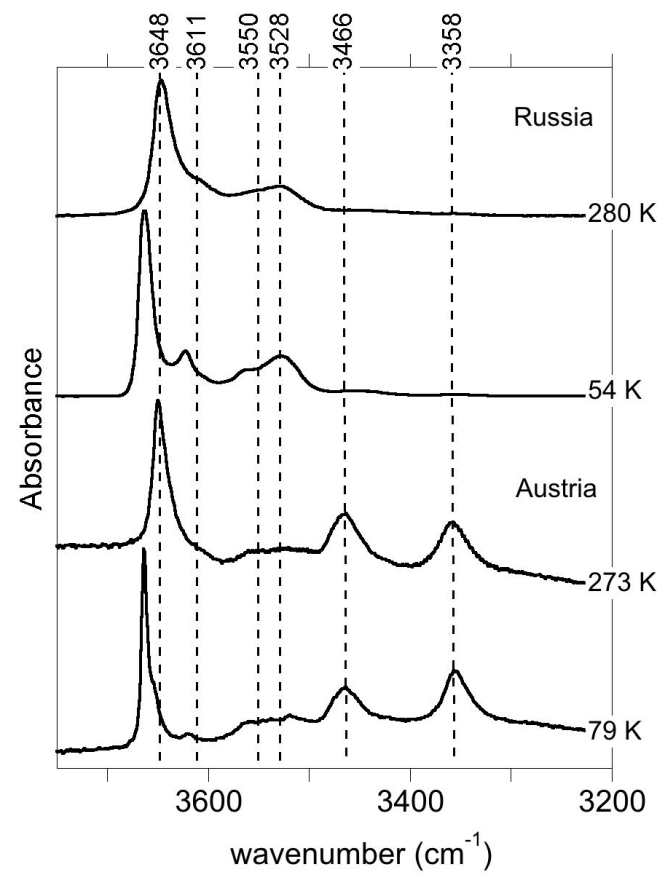

Figure 1. Infrared absorption spectra of Russian and Austrian diopside samples recorded at near-ambient and low temperatures. Note the significant positive shift and narrowing of the bands observed at frequencies above $3600 \mathrm{~cm}^{-1}$.

$3623 \mathrm{~cm}^{-1}$ at low temperature $\left(+8 \mathrm{~cm}^{-1}\right)$, and an additional component is revealed at $3655 \mathrm{~cm}^{-1}$ in the Austrian sample. In the Russian sample, this additional component is not resolved but explains the asymmetry of the $3663 \mathrm{~cm}^{-1}$ band. Note that the different recording temperature of the Russian (54 K) and Austrian (79 K) samples should not affect the relative position of the bands by more than $2 \mathrm{~cm}^{-1}$.

\subsection{Theoretical models of $\mathrm{OH}$ defects}

The structure of diopside (Fig. 2a) displays single chains of $\mathrm{SiO}_{4}$ tetrahedra ( $\mathrm{T}$ sites) parallel to the $c$ axis. The $\mathrm{Mg}^{2+}$ cations sit in chains of edge-sharing octahedra (M1 sites) between the apices of the tetrahedra. The 8-fold coordinated $\mathrm{Ca}^{2+}$ cations occupy larger M2 sites forming chains between the bases of the tetrahedra. Both M1 and M2 sites are located on a 2-fold symmetry axis parallel to the [010] direction. Three nonequivalent oxygen atoms occur in the structure. The $\mathrm{O} 1$ oxygen corresponds to the apex of silicate tetrahedra and is connected to two M1 cations and one T cation. The $\mathrm{O} 2$ oxygen is linked to one $\mathrm{T}$, one M1 and one M2 cation resulting in some degree of underbonding. In contrast, the O3 oxygen bridges two T cations and is slightly overbonded due to the proximity of the M2 cation. Starting configurations of neutral OH-bearing defects related to cation vacancies or chemical impurities have thus been constructed based on an educated guess assuming that protons are preferentially located in the proximity of the most severely underbonded 


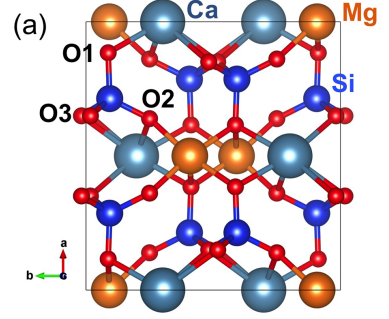

(c)

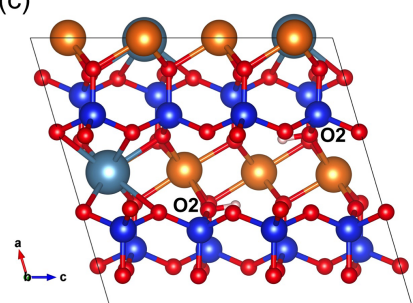

(b)

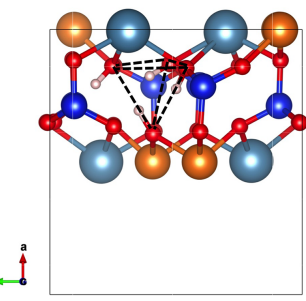

(d)

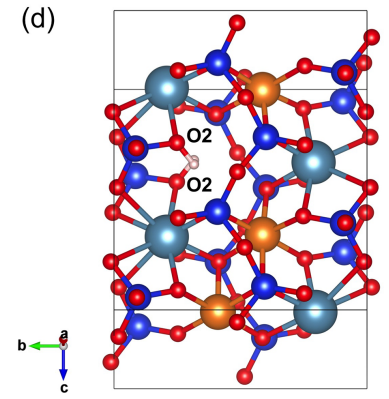

Figure 2. (a) Structure of diopside viewed along the [001] direction. (b) Structure of the $\left(4 \mathrm{H}^{+}\right)_{\mathrm{Si}}^{\times}$defect in diopside viewed along the [001] direction (model 1, Table 1). (c) Structure of the $\left(2 \mathrm{H}^{+}\right)_{\mathrm{M} 2}^{\times}$defect in diopside viewed along the [010] direction (model 2, Table 1). Note the two O2-H groups lying in the (001) plane. (d) Structure of the $\left(2 \mathrm{H}^{+}\right)_{\mathrm{M} 1}^{\times}$defect in diopside viewed along the [100] direction (model 4, Table 1). Atom colors - Si: blue; oxygen: red; Mg: orange; $\mathrm{Ca}$ : greyish blue; $\mathrm{H}$ : light pink.

oxygens. The theoretical properties of $\mathrm{OH}$ groups in relaxed models are summarized in Tables 1 and 2.

\subsubsection{OH-bearing defects driven by vacant or substituted tetrahedral sites}

The charge compensation requirements related to the removal of a $\mathrm{Si}^{4+}$ cation from a $\mathrm{T}$ site can be ensured by the addition of four protons forming four hydroxyl groups associated with the vacant $\mathrm{T}$ site. In the relaxed configuration of the $\left(4 \mathrm{H}^{+}\right)_{\mathrm{Si}}^{\times}$defect (model 1, Table 1, Fig. 2b), one of the $\mathrm{OH}$ group points out of the $\mathrm{T}$ site leading to a relatively short $\mathrm{O}-$ $\mathrm{H}$ distance and a high $\mathrm{OH}$ stretching frequency $\left(3720 \mathrm{~cm}^{-1}\right)$. The three other $\mathrm{OH}$ groups form $\mathrm{H}$ bonds along the edges of the $\mathrm{T}$ site and lead to three vibrational modes between 3300 and $3500 \mathrm{~cm}^{-1}$ involving the coupled motion of $\mathrm{H}$ atoms. The intensity of the bands at lower frequency is significantly stronger than that of the $3720 \mathrm{~cm}^{-1}$ band (Fig. A1).

Another more complex mechanism ensuring the charge compensation of an $\mathrm{Si}$ vacancy can involve two protons and a nearby $\mathrm{Ti}^{4+}$ for $\mathrm{Mg}^{2+}$ substitution, leading to a $\left[\left(2 \mathrm{H}^{+}\right)_{\mathrm{Si}}\left(\mathrm{Ti}^{4+}\right)_{\mathrm{M} 1}\right]^{\times}$stoichiometry. Among the potential configurations (Appendix B), the most stable one (model 19, Table 1) leads to stretching frequencies of 3352 and $3494 \mathrm{~cm}^{-1}$ with dominant polarization along $u \gamma$ and $(u \alpha>u \beta)$, respectively.

Tetrahedral sites in diopside are also commonly occupied by trivalent cations such as $\mathrm{Al}^{3+}$ and $\mathrm{Fe}^{3+}$. The $\mathrm{M}^{3+}$ for $\mathrm{Si}^{4+}$ substitution requires the addition of one proton to ensure the charge compensation, the underbonded $\mathrm{O} 2$ atom appearing to be the most favorable site for the proton location. A previous modeling of this defect using empirical potentials also proposed the $\mathrm{O} 2$ atom as the most favorable docking site for the proton in this coupled substitution scheme (Gatzemeier and Wright, 2006). The O2-H group in the relaxed $\left(\mathrm{Al}^{3+}, \mathrm{H}^{+}\right)_{\mathrm{Si}}^{\times}$model (model 5, Table 1) forms a weak $\mathrm{H}$ bond with an $\mathrm{O} 3$ atom and displays a relatively short $\mathrm{O} 2-\mathrm{H}$ length $(0.969 \AA)$, leading to a stretching band at $3688 \mathrm{~cm}^{-1}$. The band is strongly pleochroic with a very weak contribution for polarization parallel to $u \gamma$. The incorporation of a $\mathrm{Fe}^{3+}$ ion instead of $\mathrm{Al}^{3+}$ leads to a very similar geometry and almost identical vibrational properties (model 6, Table 1).

Additional models displaying trivalent cations in tetrahedral sites have been obtained by substituting the neighboring $\mathrm{Ca}^{2+}$ ion with a smaller $\mathrm{Mg}^{2+}$ or $\mathrm{Fe}^{2+}$ ion $-\left[\left(\mathrm{Al}^{3+}, \mathrm{H}^{+}\right)_{\mathrm{Si}}\left(\mathrm{Mg}^{2+}\right)_{\mathrm{M} 2}\right]^{\times},\left[\left(\mathrm{Al}^{3+}, \mathrm{H}^{+}\right)_{\mathrm{Si}}\left(\mathrm{Fe}^{2+}\right)_{\mathrm{M} 2}\right]^{\times}$. The occurrence of $\mathrm{Fe}^{2+}$ ion in the M2 site of diopside has been reported by, for example, Andrut et al. (2003). Although the orientation of the $\mathrm{O} 2-\mathrm{H}$ group is similar to that observed in the $\left(\mathrm{Al}^{3+}, \mathrm{H}^{+}\right)_{\mathrm{Si}}^{\times}$model, the modification of the local environment increases the $\mathrm{O} 2-\mathrm{H}$ distance by $\sim 0.002 \AA$ and decreases the $\mathrm{OH}$ stretching frequency by 20 to $33 \mathrm{~cm}^{-1}$ (models 25 and 26, Table 2). In contrast, the $\mathrm{Fe}^{2+}$ for $\mathrm{Mg}^{2+}$ substitution in the neighboring M1 site increases the $\mathrm{OH}$ stretching frequency by $20 \mathrm{~cm}^{-1}$ (model 24, Table 2).

\subsubsection{OH-bearing defects driven by vacancies or impurities in the $\mathrm{M} 2$ site}

The charge compensation related to the removal of a $\mathrm{Ca}^{2+}$ cation from the M2 site can be ensured by the addition of two protons, preferentially on the two severely underbonded $\mathrm{O} 2$ oxygens. Locating the two hydrogen atoms on $\mathrm{O} 1$ atoms leads to a less stable configuration (by $75 \mathrm{~kJ} \mathrm{~mol}^{-1}$ ), which does not confirm the preferred protonation of $\mathrm{O} 1$ atoms in M2 vacancies previously suggested by Gatzemeier and Wright (2006). After relaxation, the two symmetric O2-H groups of the $\left(2 \mathrm{H}^{+}\right)_{\mathrm{M} 2}^{\times}$model are nearly parallel to the $c$ axis with a slight canting in the (100) plane (Fig. 2c). They share relatively long $\mathrm{H}$ bonds $(2.14 \AA$ ) with the $\mathrm{O} 1$ atoms. Two stretching modes are observed at 3410 and $3413 \mathrm{~cm}^{-1}$, with polarizations parallel and perpendicular to the $b$ axis, respectively (model 2 , Table 1 ).

Sodium incorporation in the M2 site of diopside is common and mostly due to the coupled $\mathrm{Na}^{+}$for $\mathrm{Ca}^{2+}$ and $\mathrm{Al}^{3+}$ for $\mathrm{Mg}^{2+}$ substitutions (jadeite-type substitution). However, the charge compensation of the $\mathrm{Na}^{+}$for $\mathrm{Ca}^{2+}$ substitution can also be ensured by the addition of a proton near the M2 site. In this case, and consistent with the findings of Gatzemeier and Wright (2006), the underbonded O2 atom was considered the favored site for the proton location. After re- 


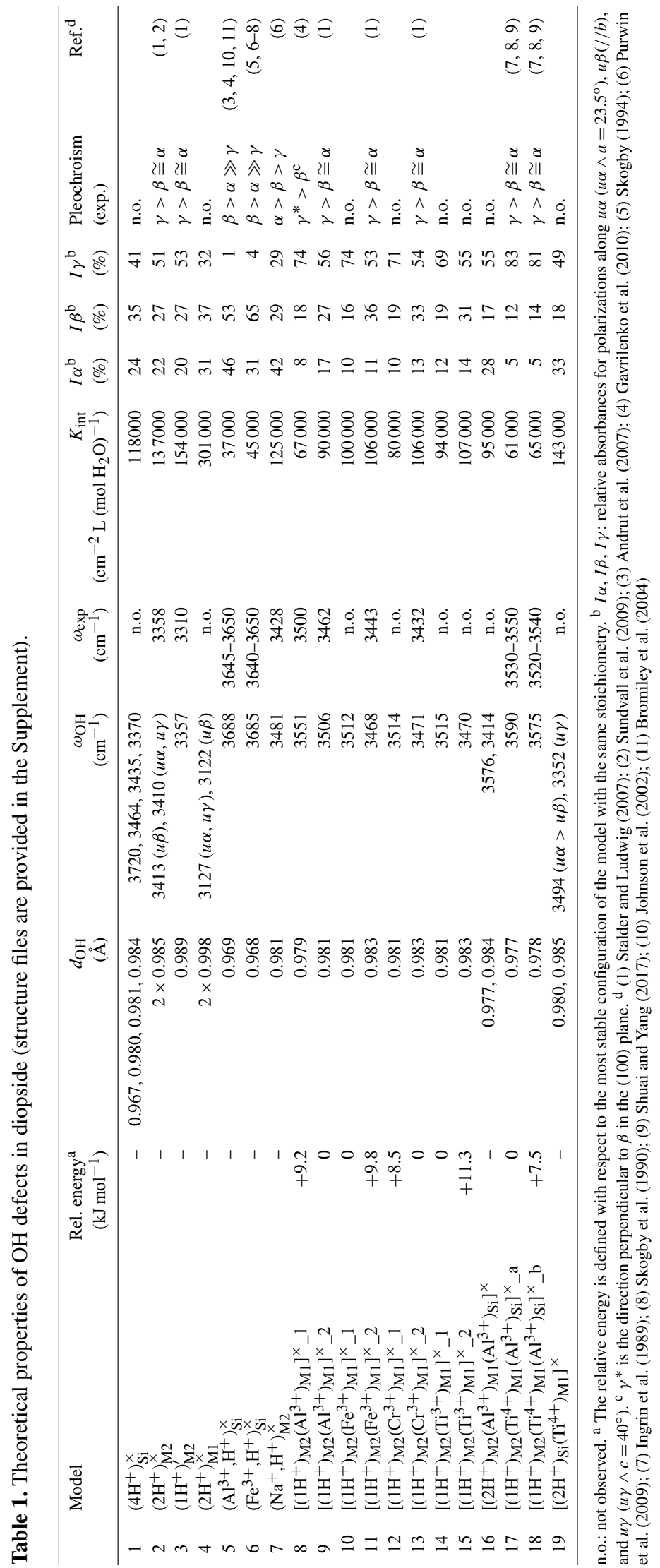


Table 2. Theoretical properties of selected defects with nearby isovalent substitutions (structure files are provided in the Supplement).

\begin{tabular}{|c|c|c|c|c|c|}
\hline & Model & $\begin{array}{l}\text { Rel. energy }{ }^{\mathrm{a}} \\
\left(\mathrm{kJ} \mathrm{mol}^{-1}\right)\end{array}$ & $\begin{array}{r}d_{\mathrm{O}-\mathrm{H}} \\
(\AA)\end{array}$ & $\begin{array}{r}\omega_{\mathrm{OH}} \\
\left(\mathrm{cm}^{-1}\right)\end{array}$ & $\begin{array}{r}\text { Shift }^{\mathrm{d}} \\
\left(\mathrm{cm}^{-1}\right)\end{array}$ \\
\hline 20 & {$\left[\left(2 \mathrm{H}^{+}\right)_{\mathrm{M} 2}\left(\mathrm{Fe}^{2+}\right)_{\mathrm{M} 1}\right]^{\times}$asym $^{\mathrm{c}}$} & 0 & $0.989,0.984$ & 3329,3424 & $-81,+14$ \\
\hline 21 & {$\left[\left(2 \mathrm{H}^{+}\right)_{\mathrm{M} 2}\left(\mathrm{Fe}^{2+}\right)_{\mathrm{M} 1}\right]^{\times} \mathrm{sym}^{\mathrm{c}}$} & 2.0 & $0.987,0.987$ & 3385,3388 & $-25,-22$ \\
\hline 22 & {$\left[\left(2 \mathrm{H}^{+}\right)_{\mathrm{M} 1}\left(\mathrm{Fe}^{2+}\right)_{\mathrm{M} 1}\right]^{\times}$} & - & $1.005,0.998$ & 2989,3121 & $-138,-6$ \\
\hline 23 & {$\left[\left(2 \mathrm{H}^{+}\right)_{\mathrm{M} 2}\left(\mathrm{Ti}^{4+}\right)_{\mathrm{Si}}\right]^{\times}$} & - & $1.000,0.985$ & 3098,3421 & $-312,+11$ \\
\hline 24 & {$\left[\left(\mathrm{Al}^{3+}, \mathrm{H}^{+}\right)_{\mathrm{Si}}\left(\mathrm{Fe}^{2+}\right)_{\mathrm{M} 1}\right]^{\times}$} & - & 0.967 & 3708 & +20 \\
\hline 25 & {$\left[\left(\mathrm{Al}^{3+}, \mathrm{H}^{+}\right)_{\mathrm{Si}}\left(\mathrm{Fe}^{2+}\right)_{\mathrm{M} 2}\right]^{\times}$} & - & 0.971 & 3655 & -33 \\
\hline 26 & {$\left[\left(\mathrm{Al}^{3+}, \mathrm{H}^{+}\right)_{\mathrm{Si}}\left(\mathrm{Mg}^{2+}\right)_{\mathrm{M} 2}\right]^{\times}$} & - & 0.970 & 3668 & -20 \\
\hline 27 & {$\left[\left(1 \mathrm{H}^{+}\right)_{\mathrm{M} 2}\left(\mathrm{Al}^{3+}\right)_{\mathrm{M} 1}\left(\mathrm{Fe}^{2+}\right)_{\mathrm{M} 1}\right]^{\times}{ }_{1} 1$} & 11.4 & 0.978 & 3561 & +10 \\
\hline 28 & {$\left[\left(1 \mathrm{H}^{+}\right)_{\mathrm{M} 2}\left(\mathrm{Al}^{3+}\right)_{\mathrm{M} 1}\left(\mathrm{Fe}^{2+}\right)_{\mathrm{M} 1}\right]^{\times}{ }_{2}$} & 0 & 0.980 & 3523 & +17 \\
\hline 29 & {$\left[\left(1 \mathrm{H}^{+}\right)_{\mathrm{M} 2}\left(\mathrm{Al}^{3+}\right)_{\mathrm{M} 1}\left(\mathrm{Ti}^{4+}\right)_{\mathrm{Si}}\right]^{\times}{ }_{-1}$} & $18.2^{\mathrm{b}}$ & 0.979 & 3559 & +8 \\
\hline 30 & {$\left[\left(1 \mathrm{H}^{+}\right)_{\mathrm{M} 2}\left(\mathrm{Al}^{3+}\right)_{\mathrm{M} 1}\left(\mathrm{Ti}^{4+}\right)_{\mathrm{Si}}\right]^{\times}{ }_{2} 2$} & $8.7^{\mathrm{b}}$ & 0.981 & 3517 & +11 \\
\hline
\end{tabular}

a The relative energy is defined with respect to the most stable configuration of the model with the same stoichiometry. ${ }^{b}$ Reference is model 17. ${ }^{\mathrm{c}}$ In the asymmetric configuration, the 2-fold site symmetry is broken, while it is preserved in the symmetric configuration. ${ }^{\mathrm{d}}$ The shift is calculated with respect to the related model without isovalent substitution (Table 1). For models displaying two close frequencies, the frequency of the $(u, u)$ polarization has been considered.
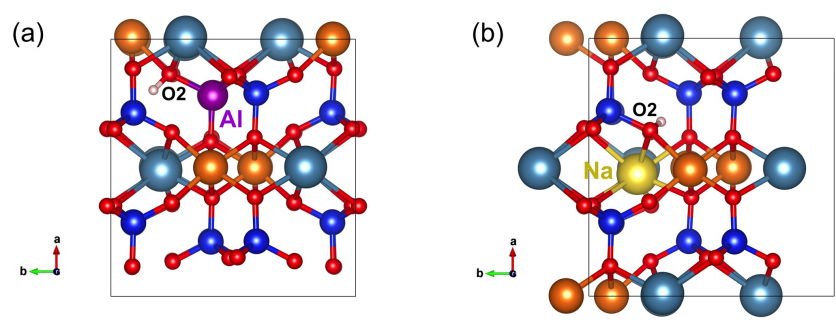

(c)

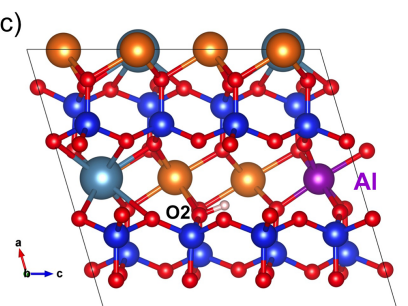

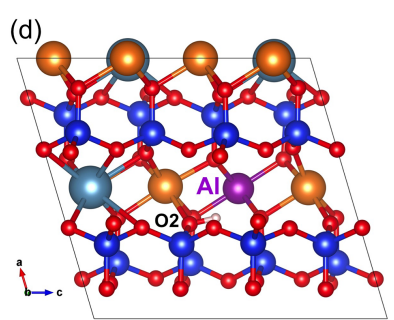

Figure 3. (a) Structure of $\left(\mathrm{Al}^{3+}, \mathrm{H}^{+}\right)_{\mathrm{Si}}^{\times}$defect in diopside viewed along the [001] direction (model 5, Table 1). (b) Structure of the $\left(\mathrm{Na}^{+}, \mathrm{H}^{+}\right)_{\mathrm{M} 2}^{\times}$defect in diopside viewed along the [001] direction (model 7, Table 1). (c) Structure of the $\left[\left(1 \mathrm{H}^{+}\right)_{\mathrm{M} 2}(\mathrm{Al})_{\mathrm{M} 1}\right]^{\times}{ }_{-} 1 \mathrm{de}-$ fect in diopside viewed along the [010] direction (model 8, Table 1). (d) Structure of the $\left[\left(1 \mathrm{H}^{+}\right)_{\mathrm{M} 2}(\mathrm{Al})_{\mathrm{M} 1}\right]^{\times}{ }_{2} 2$ defect in diopside viewed along the [010] direction (model 9, Table 1). Atom colors are the same as in Fig. 2.

laxation (Fig. 3b), the corresponding model leads to a band at $3481 \mathrm{~cm}^{-1}$ with the following pleochroism: $E / / u \alpha>$ $E / / u \beta \approx E / / u \gamma$ (model 7, Table 1$)$.

To complete the picture, a series of M2 vacancy models in which the charge compensation is only partially ensured by one $\mathrm{H}^{+}$have been considered. In this case, several mechanisms can balance the remaining charge of the defect.

Trivalent cations are commonly incorporated in the smaller octahedral M1 sites of diopside. The corresponding charge excess can contribute to the compensation of neighboring M2 vacancies. Models of M2 vacancies displaying a single $\mathrm{OH}$ group and associated with trivalent cations $\left(\mathrm{Al}^{3+}\right.$, $\mathrm{Fe}^{3+}, \mathrm{Cr}^{3+}$ and $\left.\mathrm{Ti}^{3+}\right)$ in $\mathrm{M} 1$ sites have thus been considered (models 8-15, Table 1). Two cationic configurations occur depending on the relative position of the vacant M2 and substituted M1 sites. Not considering the proton location, the 2-fold symmetry of the M2 site is broken in configuration 1 (Fig. 3c), while it is preserved in configuration 2 (Fig. 3d). In the $\mathrm{Al}$ substituted models, configuration 2 is more stable than configuration 1 by $\sim 9 \mathrm{~kJ} \mathrm{~mol}^{-1}$ (models 9 and 8 , Table 1). Compared with configuration 1, configuration 2 displays a longer $\mathrm{O} 2-\mathrm{H}$ bond and a $45 \mathrm{~cm}^{-1}$ lower stretching frequency. For a given configuration, the replacement of $\mathrm{Al}^{3+}$ by $\mathrm{Fe}^{3+}, \mathrm{Cr}^{3+}$ or $\mathrm{Ti}^{3+}$ cations decreases the $\mathrm{O} 2-\mathrm{H}$ frequency by $\sim 40 \mathrm{~cm}^{-1}$. The vibrational and spectroscopic properties of the $\mathrm{Cr}^{3+}-$ and $\mathrm{Ti}^{3+}$-bearing models are almost identical.

The charge neutrality of an M2 vacancy only displaying one $\mathrm{H}^{+}$can also be ensured by an electrostatic countercharge homogeneously distributed over the volume of the supercell. This procedure is expected to mimic a more remote charge compensation mechanism, weakly affecting the local geometry of the defect. In the relaxed $\left(1 \mathrm{H}^{+}\right)_{\mathrm{Ca}}^{\prime}$ model, the orientation of the remaining $\mathrm{O} 2-\mathrm{H}$ group is similar to that observed for the $\left(2 \mathrm{H}^{+}\right)_{\mathrm{M} 2}^{\times}$configuration, but the $\mathrm{O} 2-\mathrm{H}$ bond is slightly longer, decreasing its stretching frequency to $3357 \mathrm{~cm}^{-1}$ (model 3, Table 1).

More complex configurations modifying the local environment of $\mathrm{M} 2$ vacancies displaying two $\mathrm{OH}$ groups have also been investigated. The Tschermak substitution involves the coupled substitution of two $\mathrm{Al}^{3+}$ for one $\mathrm{Si}^{4+}$ and one 

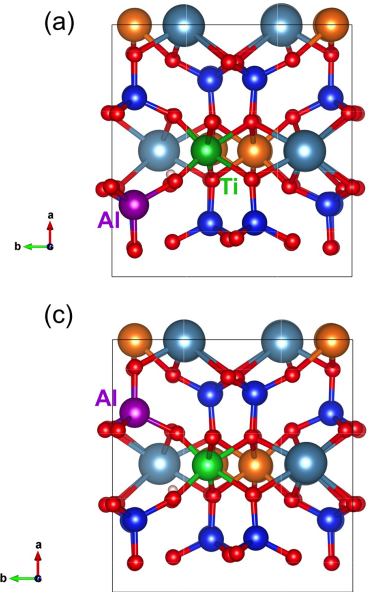

(b)

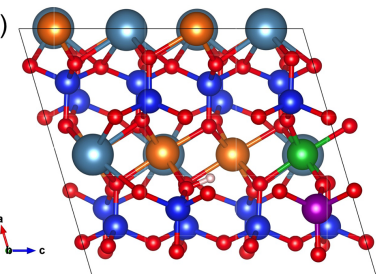

(d)

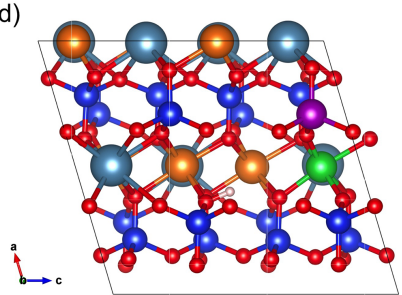

Figure 4. (a,b) Structure of $\left[\left(2 \mathrm{H}^{+}\right)_{\mathrm{M} 2}\left(\mathrm{Ti}^{4+}\right)_{\mathrm{M} 1}\left(\mathrm{Al}^{3+}\right)_{\mathrm{Si}}\right]^{\times}{ }_{-} \mathrm{a}$ defect in diopside viewed along the [001] (a) and [010] (b) directions (model 17, Table 1). (c, d) Structure of $\left[\left(2 \mathrm{H}^{+}\right)_{\mathrm{M} 2}\left(\mathrm{Ti}^{4+}\right)_{\mathrm{M} 1}\left(\mathrm{Al}^{3+}\right)_{\mathrm{Si}}\right]^{\times}$b defect in diopside viewed along the [001] (c) and [010] (d) directions (model 18, Table 1). Atom colors are the same as in Fig. 2.

$\mathrm{Mg}^{2+}$ ion, thus ensuring electrostatic neutrality. It is a common feature of Al-bearing pyroxenes (e.g., Deer et al., 1978). In this case, a relatively large number of cationic configurations can occur, depending on the relative locations of the vacant M2, tetrahedral Al and octahedral Al sites. Five M2 vacancy models with a Tschermak-type environment have been tested. In all the models, the 2-fold symmetry is broken leading to two $\mathrm{OH}$ groups with distinct spectroscopic properties. In the most stable configuration (model 16, Table 1), the length $(0.984 \AA)$ and stretching frequency $\left(3414 \mathrm{~cm}^{-1}\right)$ of the $\mathrm{OH}$ group located between the two $\mathrm{Al}$ sites are similar to those determined for the $\left(2 \mathrm{H}^{+}\right)_{\mathrm{M} 2}^{\times}$model. In contrast, the $\mathrm{O}-\mathrm{H}$ distance of the other group decreases to $0.977 \AA$, and its frequency increases to $3576 \mathrm{~cm}^{-1}$. The other four models also displayed a splitting of the two $\mathrm{OH}$ stretching frequencies with one occurring in the $3425-3356 \mathrm{~cm}^{-1}$ range and the other increasing to the $3510-3580 \mathrm{~cm}^{-1}$ range. Similar to the Tschermak-type configurations, a series of M2 vacancy models displaying a tetrahedral $\mathrm{Al}^{3+}$ associated with $\mathrm{a} \mathrm{Ti}^{4+}$ ion in a neighboring M1 site were investigated. In this case, only one $\mathrm{OH}$ group ensures a local electrostatic neutrality of the defect (Fig. 4). The two most stable configurations only differ by $7.5 \mathrm{~kJ} \mathrm{~mol}^{-1}$ (models 17 and 18 , Table 1 ). The $\mathrm{O}-\mathrm{H}$ distances are still close to $0.977 \AA$ leading to stretching frequencies of 3575 and $3590 \mathrm{~cm}^{-1}$. Chemically equivalent models with inverted cationic configurations (models 29 and 30, Table 2), i.e., tetrahedral $\mathrm{Ti}^{4+}$ and octahedral $\mathrm{Al}^{3+}$, are not energetically favored and display stretching frequencies close to their counterparts with full $\mathrm{Si}$ occupancy $-\left[\left(1 \mathrm{H}^{+}\right)_{\mathrm{M} 2}\left(\mathrm{Al}^{3+}\right)_{\mathrm{M} 1}\right]^{\times} \_1$ and $\left[\left(1 \mathrm{H}^{+}\right)_{\mathrm{M} 2}\left(\mathrm{Al}^{3+}\right)_{\mathrm{M} 1}\right]^{\times} \_2(\mathrm{Ta}-$ ble 1).

Finally, models displaying a Fe$e^{2+}$ for $\mathrm{Mg}^{2+}$ substitution in the vicinity of $\mathrm{Ca}$ vacancies have been examined (models 20 and 21, Table 2). In the $\left[\left(2 \mathrm{H}^{+}\right)_{\mathrm{M} 2}\left(\mathrm{Fe}^{2+}\right)_{\mathrm{M} 1}\right]^{\times}$model with asymmetric cationic configuration, the stretching frequency of the $\mathrm{OH}$ group in the coordination sphere of the $\mathrm{Fe}^{2+}$ cation increases by $14 \mathrm{~cm}^{-1}$, while the other decreases by $81 \mathrm{~cm}^{-1}$. In the symmetric configuration, the two $\mathrm{OH}$ frequencies decrease by $22-25 \mathrm{~cm}^{-1}$. In this case, none of the $\mathrm{OH}$ groups are directly bonded to $\mathrm{Fe}^{2+}$.

\subsubsection{OH-bearing defects driven by vacancies in the M1 site}

The underbonding of oxygen atoms resulting from the removal of the central cation from an octahedral M1 site is significantly stronger for the two $\mathrm{O} 2$ atoms than for the other four $\mathrm{O} 1$ atoms. The relaxed $\left(2 \mathrm{H}^{+}\right)_{\mathrm{M} 1}^{\times}$model (model 4, Table 1) displays two symmetric $\mathrm{O} 2-\mathrm{H}$ groups parallel to the (100) plane and forming hydrogen bonds with neighboring O1 atoms. This model leads to two stretching modes at 3122 and $3127 \mathrm{~cm}^{-1}$ with polarizations parallel and perpendicular to the $b$ axis, respectively. As for the vacant M2 site, additional models of M1 vacancies involving nearby cationic substitutions have also been explored. They will not be discussed in further detail here because their low stretching frequencies $\left(<3200 \mathrm{~cm}^{-1}\right)$ do not seem to correspond to any experimental observation on diopside. For example, the $\mathrm{Fe}^{2+}$ for $\mathrm{Mg}^{2+}$ substitution in the neighboring M1 site leads to frequencies of 3121 and $2989 \mathrm{~cm}^{-1}$ (model 22, Table 2).

\section{Discussion: interpretation of experimental observations}

\subsection{General properties of $\mathrm{OH}$-bearing defects in diopside}

The observed correlations between the geometry, the stretching frequency and the infrared absorption coefficient of $\mathrm{OH}$ groups in diopside (Figs. 5 and 6) are consistent with previous studies performed at the same theoretical level (e.g., Balan et al., 2008, 2011) except for a frequency shift of $\sim+50 \mathrm{~cm}^{-1}$ due to the use of different pseudopotentials. It is expected that the theoretical stretching frequencies obtained in the present study overestimate the frequencies experimentally observed at ambient temperature by typically 10 to $50 \mathrm{~cm}^{-1}$, as observed in quartz (Jollands et al., 2020). A stronger overestimation, amounting to $125 \mathrm{~cm}^{-1}$, has, however, been recently observed for $\mathrm{OH}$ defects in corundum (Balan, 2020). We will see in the following that the theoretical frequencies of $\mathrm{OH}$ defects in diopside are systematically upshifted by $\sim 50 \mathrm{~cm}^{-1}$ compared to their experimental counterparts (Fig. 7).

The relation between the stretching frequency and the infrared absorption coefficient of $\mathrm{OH}$ groups challenges the use of a single absorption coefficient value for water quan- 


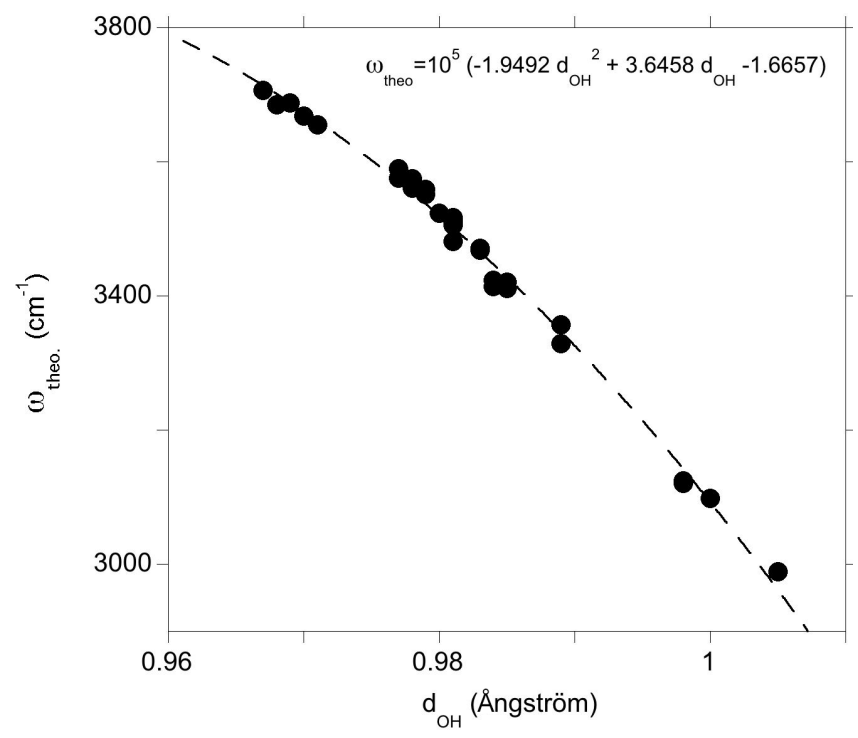

Figure 5. Theoretical $\mathrm{OH}$-stretching frequency $\left(\omega_{\text {theo }}\right)$ as a function of the $\mathrm{O}-\mathrm{H}$ distance $\left(d_{\mathrm{OH}}\right)$. The dotted line corresponds to a quadratic fit of the data serving as a guide for the eye.

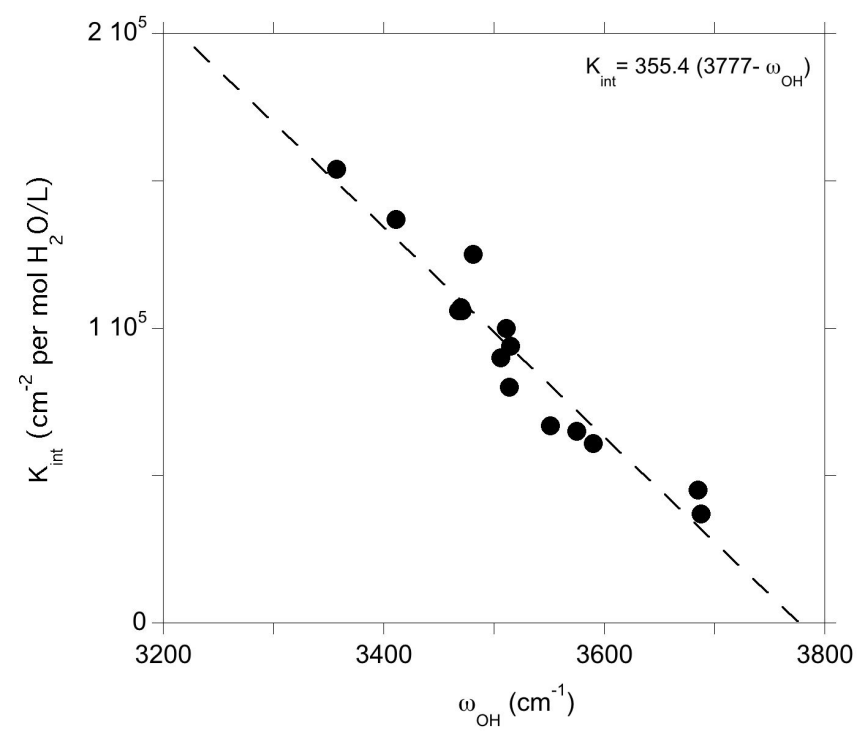

Figure 6. Theoretical integrated absorption coefficient $\left(K_{\text {int }}\right)$ of $\mathrm{OH}$ stretching mode as a function of frequency $\left(\omega_{\mathrm{OH}}\right)$. Models displaying multiple bands (models 1, 16 and 19, Table 1) or a frequency significantly lower than those experimentally observed (model 4, Table 1) have not been included in the figure.

tification in pyroxenes and supports the use of wavelengthdependent calibrations. Furthermore, the observed scattering of the data indicates that defects with relatively close stretching frequencies can display significantly different absorption coefficients. For example, the $\left(\mathrm{Na}^{+}, \mathrm{H}^{+}\right)_{\mathrm{M} 2}^{\times}$and $\left[\left(1 \mathrm{H}^{+}\right)_{\mathrm{M} 2}\left(\mathrm{Fe}^{3+}\right)_{\mathrm{M} 1}\right]^{\times} \_1$ models (models 7 and 10 , Table 1) are observed at 3481 and $3512 \mathrm{~cm}^{-1}$ and display absorption

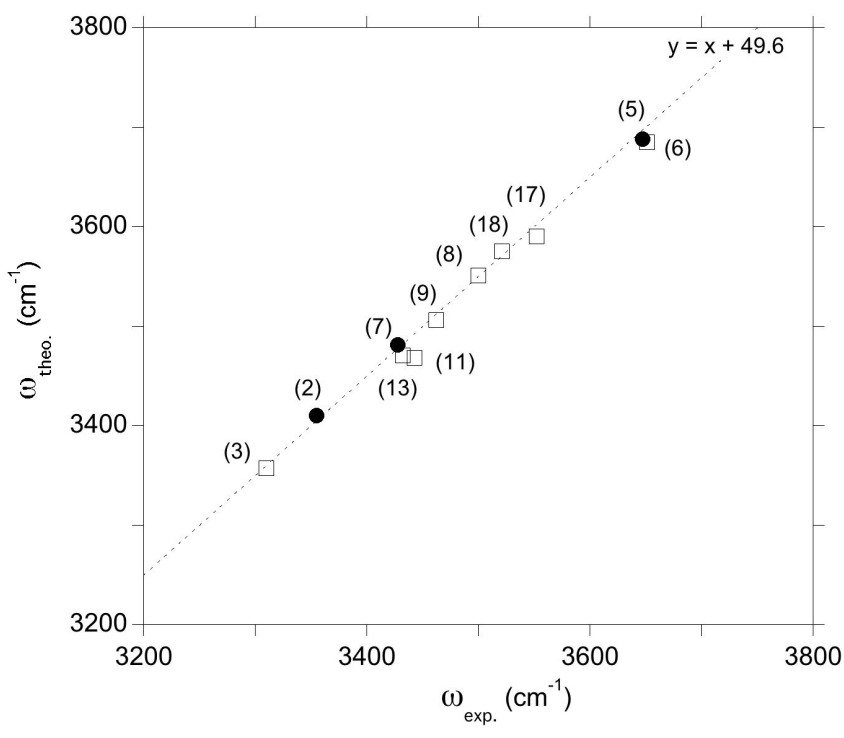

Figure 7. Theoretical stretching frequency of $\mathrm{OH}$ groups as a function of experimental frequency for the series of relevant models. The labels refer to the models of Table 1 . The $1: 1$ correlation has been obtained only using models (5), (7) and (2) (full circles). Alignment of the other models (open squares) in this correlation supports the proposed interpretations (see text).

coefficients of 125000 and $100000 \mathrm{~cm}^{-2} \mathrm{~L}\left(\mathrm{~mol} \mathrm{H}_{2} \mathrm{O}\right)^{-1}$, respectively. On the experimental side, significant differences of absorption coefficients have been reported for omphacite and augite by Katayama et al. (2006) and Bell et al. (1995) (83400 vs. $38300 \mathrm{~cm}^{-2} \mathrm{~L}\left(\mathrm{~mol} \mathrm{H}_{2} \mathrm{O}\right)^{-1}$, respectively) despite a moderate variation in average stretching frequencies (3475 vs. $3540 \mathrm{~cm}^{-1}$, respectively). Accordingly, the present results suggest that improvements in water quantification would require a proper identification of the defects related to the observed bands and the establishment of proper site-specific $\mathrm{OH}$ absorption coefficients, as previously done, for example, for olivine (Kovács et al., 2010).

\subsection{OH defects in pure diopside}

Experimental spectra of $\mathrm{OH}$-bearing synthetic diopside have been reported by Stalder and Ludwig (2007) and Sundvall et al. (2009). Under saturated silica conditions, the spectrum is dominated by a band at $3355 \mathrm{~cm}^{-1}$ with absorbances following the order $E / / \gamma>E / / \alpha \approx E / / \beta$. The properties of the observed band are thus consistent with those computed for the $\left(2 \mathrm{H}^{+}\right)_{\mathrm{M} 2}^{\times}$model at 3410 and $3413 \mathrm{~cm}^{-1}$ (model 2, Table 1). Interestingly, the theoretical results indicate that the band observed for the $E / / \beta$ polarization should be shifted by a few wavenumbers toward the high frequencies with respect to the bands observed for polarizations in the perpendicular plane. Although this minor shift can go unnoticed in experimental spectra recorded with a $4 \mathrm{~cm}^{-1}$ resolution, this 
theoretical prediction could be tested in future experimental works.

A weak and broad band without clearly defined pleochroism can also occur at $3230 \mathrm{~cm}^{-1}$ in the experimental spectra of pure diopside (Sundvall et al., 2009). However, it does not match any of the presently investigated models. In particular, it does not correspond to the properties of the $\left(2 \mathrm{H}^{+}\right)_{\mathrm{M} 1}^{\times}$defects which should occur at significantly lower frequencies. It can also be noticed that lower frequencies are correlated to stronger absorption coefficients. Accordingly, it is unlikely that hydrous vacancies in the M1 site occur in significant proportions in pure diopside without being noticed. This observation is consistent with the previous conclusions made for enstatite that hydrous $M$ vacancies are preferentially associated with the M2 site (Stalder et al., 2012; Balan et al., 2012).

Hydrogarnet-type defects corresponding to four hydroxyl groups located at a tetrahedral site have been reported and modeled in a number of orthosilicates such as garnet (e.g., Nobes et al., 2000, Geiger and Rossman, 2018), zircon (Nasdala et al., 2001., Balan et al., 2013) and forsterite (Lemaire et al., 2004; Berry et al., 2005; Balan et al., 2011, 2017). Based on the properties of the computed $\left(4 \mathrm{H}^{+}\right)_{\mathrm{Si}}^{\times}$model (model 1, Table 1), this type of defect should lead to a weak band at high frequency $\left(>3670 \mathrm{~cm}^{-1}\right)$ and a series of more intense bands in the $3300-3400 \mathrm{~cm}^{-1}$ range. According to the current experimental spectra, it seems unlikely that hydrogarnet-type defects occur at significant concentration levels in pure diopside.

\subsection{OH defects in Na-bearing synthetic diopside}

Experimental spectra of Na-doped diopside have been studied by Purwin et al. (2009). Compared with those of pure diopside, they display a major band at $3428 \mathrm{~cm}^{-1}$ with absorbances following the order $E / / \alpha>E / / \beta>E / / \gamma$. The properties of this band are consistent with those determined for the band at $3481 \mathrm{~cm}^{-1}$ of the $\left(\mathrm{Na}^{+}, \mathrm{H}^{+}\right)_{\mathrm{M} 2}^{\times}$model (model 7, Table 1), although the theoretical model leads to a slightly different pleochroism $(I \alpha>I \beta \cong I \gamma)$. It can be noticed that the relative intensity of the $I \alpha$ and $I \gamma$ components in the $(a, c)$ plane depends on the angles between the optic and crystal axes, a parameter which is affected by the chemical variability of pyroxenes and can differ from one sample to the other (e.g., Hess, 1949). The present theoretical model supports the hydrogen incorporation mechanism proposed by Purwin et al. (2009).

\subsection{OH defects associated with trivalent cations}

Trivalent cations in diopside can occur in tetrahedral or octahedral M1 sites. Incorporation in the M1 sites is generally favored by high silica activity. In addition, strong crystal field stabilization precludes the occurrence of $\mathrm{Cr}^{3+}$ ions in tetrahedral sites. Accordingly, the main bands observed in the spectra reported by Stalder and Ludwig (2007) should reflect the preferential incorporation of trivalent cations in M1 sites. The position of the band observed at 3462, 3443 and $3432 \mathrm{~cm}^{-1}$ depends on the nature of the trivalent cation: $\mathrm{Al}^{3+}, \mathrm{Fe}^{3+}$ and $\mathrm{Cr}^{3+}$, respectively. Its absorbance follows the order $E / / \gamma \gg E / / \beta \cong E / / \alpha$, similar to that observed for the band related to the doubly protonated M2 vacancies. According to the present results, the bands between 3462 and $3432 \mathrm{~cm}^{-1}$ can be assigned to an M2 vacancy displaying one $\mathrm{OH}$ group and a nearby trivalent cation occupying an M1 site in the less symmetric configuration $\left(\left[\left(1 \mathrm{H}^{+}\right)_{\mathrm{M} 2}\left(\mathrm{M}^{3+}\right)_{\mathrm{M} 1}\right]^{\times} \_2\right.$; models 9,11 and 13 , Table 1$)$. For $\mathrm{Al}^{3+}$ and $\mathrm{Cr}^{3+}$, the relative shift of the theoretical frequencies $\left(35 \mathrm{~cm}^{-1}\right)$ is consistent with the difference experimentally observed $\left(3462-3432=30 \mathrm{~cm}^{-1}\right)$. The agreement is less good for the $\mathrm{Fe}^{3+}$-bearing model, for which the other cationic configuration is also found to be more stable by $9 \mathrm{~kJ} \mathrm{~mol}^{-1}$ and the experimentally observed band is at a frequency $10 \mathrm{~cm}^{-1}$ higher than that observed for $\mathrm{Cr}^{3+}$. This lower agreement can most likely be ascribed to a lower performance of standard DFT calculations treating the $\mathrm{Fe}^{3+}$-bearing systems. Beside the signals related to the $\left(2 \mathrm{H}^{+}\right)_{\mathrm{M} 2}^{\times}$and $\left[\left(1 \mathrm{H}^{+}\right)_{\mathrm{M} 2}\left(\mathrm{M}^{3+}\right)_{\mathrm{M} 1}\right]^{\times}$defects, the spectra reported by Stalder and Ludwig (2007) in the presence of trivalent cations systematically display a band at $3310 \mathrm{~cm}^{-1}$ with the same pleochroism. However, this band does not depend on the nature of the trivalent cation. The best match with a theoretical model is observed for the $(1 \mathrm{H})_{\mathrm{M} 2}^{\prime}$ model (model 3, Table 1), which involves a homogeneous charge compensation. Accordingly, this band could be related to isolated $\mathrm{OH}$ groups associated with M2 vacancies and involving a more remote compensation for the remaining electrostatic charge by the trivalent cations in octahedral sites.

At variance with those of Stalder and Ludwig (2007), the infrared spectra of $\mathrm{Al}^{3+}$-bearing diopside reported by, for example, Gavrilenko et al. (2010), display a band at $3650 \mathrm{~cm}^{-1}$. This band also commonly occurs in natural diopside samples (e.g., Andrut et al., 2007; Johnson et al., 2002) and in one sample of Purwin et al. (2009) containing $\mathrm{Fe}^{3+}$. Its absorbance follows the order $E / / \beta>E / / \alpha \gg E / / \gamma$. These observations are consistent with the properties determined for the $\left(\mathrm{Al}^{3+}, \mathrm{H}^{+}\right)_{\mathrm{Si}}^{\times}$model but also with those of the $\left(\mathrm{Fe}^{3+}, \mathrm{H}^{+}\right)_{\mathrm{Si}}^{\times}$defect; the frequency shift between Al- and $\mathrm{Fe}$ bearing defects is only $3 \mathrm{~cm}^{-1}$ (models 5 and 6 , Table 1). This confirms the interpretation previously proposed by Beran (1976) and Bromiley et al. (2004). A band with similar properties is observed at $3620 \mathrm{~cm}^{-1}$ in Fe-bearing diopside (Skogby, 1994) and can also be ascribed to the $\left(\mathrm{Fe}^{3+}, \mathrm{H}^{+}\right)_{\mathrm{Si}}^{\times}$ defect geometry. Compared with the observations of Purwin et al. (2009), the significantly lower $\left(30 \mathrm{~cm}^{-1}\right)$ frequency of the band observed by Skogby (1994) may be explained by the fact that the Fe-bearing diopsides of Skogby (1994) also contain a fraction of $\mathrm{Fe}^{2+}$ ions in sites near the defect affecting the vibrational frequencies. For example, the presence of an $\mathrm{Fe}^{2+}$ ion in the nearby M2 site decreases the 


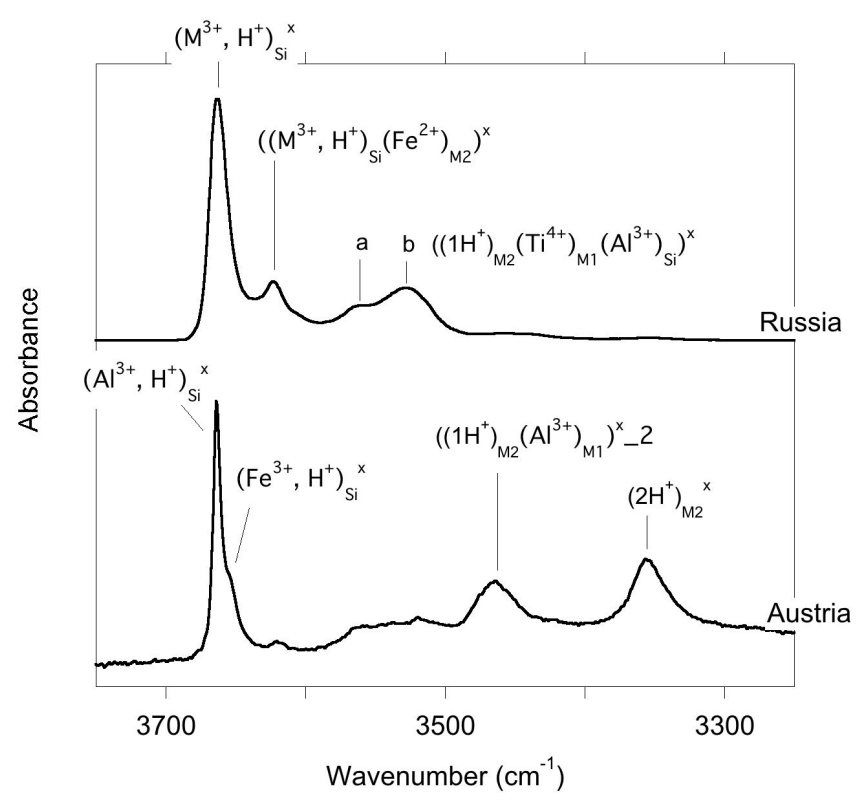

Figure 8. Band assignment in the low-temperature infrared spectra of Russian and Austrian diopside samples.

frequency of the $\left(\mathrm{Al}^{3+}, \mathrm{H}^{+}\right)_{\mathrm{Si}}^{\times}$defect by $33 \mathrm{~cm}^{-1}$ (model 25 , Table 2), and a similar frequency lowering can be expected for the $\left(\mathrm{Fe}^{3+}, \mathrm{H}^{+}\right)_{\mathrm{Si}}^{\times}$defect even though a satisfactory theoretical modeling of systems containing magnetically coupled $\mathrm{Fe}$ ions could not be obtained. In contrast, an $\mathrm{Fe}^{2+}$ ion in the nearby M1 site should increase the vibrational frequency by $20 \mathrm{~cm}^{-1}$ (model 24, Table 2). Based on these elements, the bands observed at 3663 and $3623 \mathrm{~cm}^{-1}$ in the low-temperature infrared spectrum of the Austrian and Russian samples (Fig. 8) could be related to $\left(\mathrm{M}^{3+}, \mathrm{H}^{+}\right)_{\mathrm{Si}}^{\times}$defects with $\mathrm{Ca}^{2+}$ (normal occupancy) and $\mathrm{Fe}^{2+}$ ions in the nearby M2 site, respectively; the substitution in the M2 site explains the shift of $40 \mathrm{~cm}^{-1}$ between the two bands. The theoretical shift between the $\left(\mathrm{Al}^{3+}, \mathrm{H}^{+}\right)_{\mathrm{Si}}^{\times}$or $\left(\mathrm{Fe}^{3+}, \mathrm{H}^{+}\right)_{\mathrm{Si}}^{\times}$defects is very small $\left(3 \mathrm{~cm}^{-1}\right)$ and consistent with presence of a component at $3655 \mathrm{~cm}^{-1}$, which is only resolved in the lowtemperature Austrian spectrum. Although uncertainties related to the modeling approach make it difficult to more precisely assign the two bands, the correlation observed between the $\mathrm{Al}$ content and the $3645 \mathrm{~cm}^{-1}$ band (at ambient temperature) in a zoned diopside crystal from Austria (Andrut et al., 2003) suggests that the major component at $3663 \mathrm{~cm}^{-1}$ in the low-temperature spectra is related to the $\left(\mathrm{Al}^{3+}, \mathrm{H}^{+}\right)_{\mathrm{Si}}^{\times}$defect, while the minor component at $3655 \mathrm{~cm}^{-1}$ would correspond to the $\left(\mathrm{Fe}^{3+}, \mathrm{H}^{+}\right)_{\mathrm{Si}}^{\times}$defect. Consistent with the proposed interpretation of the $3623 \mathrm{~cm}^{-1}$ band, Andrut et al. (2003) also observed a significant partitioning of $\mathrm{Fe}^{2+}$ in the M2 site in the OH-rich region of the same zoned crystal.

Finally, a sample (Al-Di976) investigated by Gavrilenko et al. (2010) displays a doublet at $\sim 3450$ and $\sim 3500 \mathrm{~cm}^{-1}$, the two components having the same pleochroic properties. As discussed above, the band at $3450 \mathrm{~cm}^{-1}$ likely corresponds to the $\left[\left(1 \mathrm{H}^{+}\right)_{\mathrm{M} 2}\left(\mathrm{Al}^{3+}\right)_{\mathrm{M} 1}\right]^{\times} \_2$ model (model 9, Table 1). Considering that the other $\left[\left(1 \mathrm{H}^{+}\right)_{\mathrm{M} 2}\left(\mathrm{Al}^{3+}\right)_{\mathrm{M} 1}\right]^{\times} \_1$ model (model 8, Table 1), with a less symmetric cationic configuration, leads to a stretching frequency $45 \mathrm{~cm}^{-1}$ higher, it is reasonable to ascribe the second component experimentally observed at $3500 \mathrm{~cm}^{-1}$ by Gavrilenko et al. (2010) to this other configuration despite its slightly higher energy $\left(\sim 9 \mathrm{~kJ} \mathrm{~mol}^{-1}\right)$.

Further constraints can be found by reporting theoretical frequencies as a function of experimental frequencies (Fig. 7). For $\mathrm{OH}$ groups not involved in strong $\mathrm{H}$ bonds, it is meaningful to assume that the discrepancy between theoretical and experimental frequencies can be roughly described by a constant shift corresponding to a $1: 1$ correlation slope. The frequency shift determined using only the $\left(2 \mathrm{H}^{+}\right)_{\mathrm{M} 2}^{\times},\left(\mathrm{Al}^{3+}, \mathrm{H}^{+}\right)_{\mathrm{Si}}^{\times}$and $\left(\mathrm{Na}^{+}, \mathrm{H}^{+}\right)_{\mathrm{M} 2}^{\times}$models (models 2 , 5 and 7 , Table 1), for which the clearest agreement between theory and experiment is observed, is $\sim 49 \mathrm{~cm}^{-1}$ (Fig. 7). Thus, the alignment of the other more complex defects on the same trend further supports the interpretations given above.

It is also noteworthy that the bands associated with trivalent cations in tetrahedral sites display a different behavior as a function of temperature compared with those involving fully or partially protonated M2 vacancies. The significant narrowing and positive shift observed at low temperature for the bands above $3600 \mathrm{~cm}^{-1}$ (Fig. 1) are similar to the anharmonic behavior observed for two $\mathrm{OH}$-stretching bands in the infrared spectrum of forsterite (Ingrin et al., 2013, 2014; Balan et al., 2017). These two bands correspond to $\mathrm{OH}$ groups pointing out of a tetrahedral site and not significantly engaged in $\mathrm{H}$ bonds, one in the $\left(4 \mathrm{H}^{+}\right)_{\mathrm{Si}}^{\times}$defect of forsterite (Balan et al., 2011) and the other in a more complex $\left(\mathrm{B}^{3+}, \mathrm{H}^{+}\right)_{\mathrm{Si}}^{\times}$defect (Ingrin et al., 2014). In the present case, the $\mathrm{OH}$ group also points out of a tetrahedral site and the $\mathrm{O}(\mathrm{H}) \ldots \mathrm{O}$ distance involving the $\mathrm{OH}$ group associated with trivalent cations is $3.38 \AA$, close to the upper limit observed between weakly $\mathrm{H}$-bonded and nonbonded $\mathrm{OH}$ entities (Libowitzky 1999; Libowitzky and Beran, 2006). By analogy with forsterite (Balan et al., 2017), the anharmonicity of some of the $\mathrm{OH}$ bands observed in the infrared spectra of diopside is thus likely related to the specificities of the atomic-scale environment of the related $\mathrm{OH}$ groups. Accordingly, the temperature-induced modifications of infrared spectra could help identify different local environments of $\mathrm{OH}$ groups in chemically more complex pyroxene samples.

\section{5 $\mathrm{OH}$ defects related to bands between 3500 and $3600 \mathrm{~cm}^{-1}$ in natural diopside}

Beside the bands observed in experimental samples, natural diopside frequently displays spectra with a series of bands between 3500 and $3600 \mathrm{~cm}^{-1}$ : one or two bands observed between 3520 and $3550 \mathrm{~cm}^{-1}$ (Skogby et al., 1990; Skogby, 2006; Shuai and Yang, 2017; Patkó et al., 2019) and a band 
at $\sim 3520 \mathrm{~cm}^{-1}$, which is frequently associated with a band at a higher frequency around $3600 \mathrm{~cm}^{-1}$ (Patkó et al., 2019; Azevedo-Vannson et al., 2020). It is difficult to propose an explanation for these bands solely based on the investigated series of relatively simple chemical models involving divalent or trivalent cations being substituted for $\mathrm{Ca}^{2+}, \mathrm{Mg}^{2+}$ or $\mathrm{Si}^{4+}$ ions. The occurrence of $\mathrm{Al}^{3+}$ in octahedral site hardly produces bands at high enough frequencies, whereas the frequency decrease $\left(33 \mathrm{~cm}^{-1}\right)$ of the $\left(\mathrm{Al}^{3+}, \mathrm{H}^{+}\right)_{\mathrm{Si}}^{\times}$model related, for example, to the presence of a $\mathrm{Mg}^{2+}$ or $\mathrm{Fe}^{2+}$ ion in the nearby M2 site is too weak. Thus, chemically more complex models should be considered. The first series of models involved an M2 vacancy associated with a local Tschermaktype environment with a pair of $\mathrm{Al}^{3+}$ ions distributed over a tetrahedral and an M1 octahedral site. These models revealed that, although the stretching of the $\mathrm{OH}$ group linked to the $\mathrm{Al}$ atoms was observed at a frequency close to or lower than those of the $\left(2 \mathrm{H}^{+}\right)_{\mathrm{M} 2}^{\times}$defect, the other group, pointing in the direction of the Al-bearing sites, displayed a frequency increase consistent with the occurrence of bands in the 3500$3600 \mathrm{~cm}^{-1}$ frequency range. However, the paired nature of the $\mathrm{OH}$ groups associated with this model was not consistent with the observation that some spectra dominated by bands between 3500 and $3600 \mathrm{~cm}^{-1}$ do not display bands in the $3350-3400 \mathrm{~cm}^{-1}$ range (e.g., Yang et al., 2019). These observations thus suggest that these bands could be related to a similar environment but with a single $\mathrm{OH}$ group occurring in the vacant $\mathrm{Ca}$ site. In this case, the defect neutrality could be locally ensured by the presence of a tetravalent cation in the octahedral site, most likely $\mathrm{Ti}^{4+}$. Depending on the investigated samples, $\mathrm{Ti}^{4+}$ appears to be distributed between tetrahedral and octahedral sites in Al-bearing diopside (Quartieri et al., 1993). As a matter of fact, the corresponding most stable models lead to stretching frequencies 69 to $90 \mathrm{~cm}^{-1}$ higher than those theoretically determined for the $\left[\left(1 \mathrm{H}^{+}\right)_{\mathrm{M} 2}\left(\mathrm{Al}^{3+}\right)_{\mathrm{M} 1}\right]^{\times} \_2 \operatorname{model}\left(3506 \mathrm{~cm}^{-1}\right)$. Considering that the experimental frequency associated with the $\left[\left(1 \mathrm{H}^{+}\right)_{\mathrm{M} 2}\left(\mathrm{Al}^{3+}\right)_{\mathrm{M} 1}\right]^{\times} \_2$ model is observed at $3462 \mathrm{~cm}^{-1}$, experimental bands associated with the Ti-bearing models are expected to occur between 3531 and $3550 \mathrm{~cm}^{-1}$, thus matching some of the frequencies frequently observed in natural samples (models 17 and 18, Table 1). Although the proposed environment is chemically complex and may seem to be unlikely at first sight, it is noteworthy that the main bands observed in natural olivine from xenolith samples are related to a complex hydrous defect involving an Si vacancy partially charge compensated by a $\mathrm{Ti}^{4+}$ ion substituted for $\mathrm{Mg}^{2+}$ in the M1 site (Walker et al., 2007; Balan et al., 2011). In the case of olivine, this configuration is allowed by the edgesharing between the M1 octahedral and the tetrahedral site. Ti-associated defects have also been reported in metamorphic garnets (Reynes et al., 2020). In this case, the electrostatic neutrality of the Si vacancy is ensured by two protons located in the tetrahedral site and two $\mathrm{Ti}^{4+}$ for $\mathrm{M}^{3+}$ substitutions in neighboring sites. In the case of diopside, the $\mathrm{T}$ site only shares a corner with the M1 site, which is occupied by an $\mathrm{M}^{2+}$ cation. This geometry precludes an efficient charge compensation of the vacant $\mathrm{T}$ site by a single $\mathrm{Ti}^{4+}$ substitution in the octahedral site, as in the $\left[\left(2 \mathrm{H}^{+}\right)_{\mathrm{Si}_{i}}\left(\mathrm{Ti}^{4+}\right)_{\mathrm{M} 1}\right]^{\times}$ model, and would favor an association of $\mathrm{Ti}^{4+}$ ions with $\mathrm{Ca}$ vacancies. Observations of the corresponding spectra in xenolith samples having experienced dehydration processes (Patkó et al., 2019) or carbonatitic metasomatism (AzevedoVanson et al., 2020) suggest that these Ti-associated centers could have a greater stability than chemically more simple defects.

Finally, the band just below $3520 \mathrm{~cm}^{-1}$ observed in some mantle diopsides by Patkó et al. (2019) and AzevedoVannson et al. (2020) could be explained by a defect of the type $\left[\left(1 \mathrm{H}^{+}\right)_{\mathrm{M} 2}\left(\mathrm{Al}^{3+}\right)_{\mathrm{M} 1}\left(\mathrm{Fe}^{2+}\right)_{\mathrm{M} 1}\right]^{\times} \_$, assuming that configuration 1 of the defect becomes energetically competitive compared to configuration 2 (models 27 and 28 , Table 2). Above, we proposed model 1 of the $\left[\left(1 \mathrm{H}^{+}\right)_{\mathrm{M} 2}\right.$ $\left.\left(\mathrm{Al}^{3+}\right)_{\mathrm{M} 1}\right]^{\times}$defect (model 8, Table 1) to explain the band at $3500 \mathrm{~cm}^{-1}$ observed in one of the synthetic Fe-free samples of Gavrilenko et al. (2010). Here again, it seems that configuration 1 remains competitive compared to configuration 2 when $\mathrm{Mg}^{2+}$ is replaced by $\mathrm{Fe}^{2+}$ in the M1 site near the defect. The co-occurrence of a band above $3450 \mathrm{~cm}^{-1}$ that could be attributed to configuration 2 in the same sample confirms that both configurations could occur at the same time. The fundamental role of $\mathrm{Fe}^{2+}$ in explaining the shift toward the high frequencies observed in natural diopsides is also supported by the occurrence of these two bands in the Fe-rich samples synthesized in Skogby (1994; sample Di5).

\section{Conclusions}

A comparison of theoretical properties of $\mathrm{OH}$-bearing defects in diopside with experimental data has confirmed previously proposed interpretations, providing a detailed picture of the defect geometry for the bands at $3647-3620 \mathrm{~cm}^{-1}$ (associated with tetrahedral $\mathrm{M}^{3+}$ ions) the bands at 3460$3432 \mathrm{~cm}^{-1}$ (associated with octahedral $\mathrm{M}^{3+}$ ions and singly protonated $\mathrm{Ca}$ vacancies), the $3420 \mathrm{~cm}^{-1}$ band (associated with the $\mathrm{Na}^{+}$for $\mathrm{Ca}^{2+}$ substitution), and the $3350 \mathrm{~cm}^{-1}$ band (associated with doubly protonated $\mathrm{Ca}$ vacancies). A more tentative interpretation has been proposed for the $3300 \mathrm{~cm}^{-1}$ band which is also likely associated with singly protonated $\mathrm{Ca}$ vacancies. For the bands between 3500 and $3600 \mathrm{~cm}^{-1}$, frequently observed in natural diopside, more complex defects need to be considered. Defects involving singly protonated $\mathrm{Ca}$ vacancies associated with tetrahedral $\mathrm{M}^{3+}$ and octahedral $\mathrm{Ti}^{4+}$ ions, as well as frequency shifts due to the substitution of $\mathrm{Fe}^{2+}$ for $\mathrm{Mg}^{2+}$ ions in the vicinity of the abovementioned defects, can be proposed. In addition, the chemical complexity of diopside, involving, for example, the common $\mathrm{Fe}^{2+}$ for $\mathrm{Mg}^{2+}$ or $\mathrm{Na}^{+}$for $\mathrm{Ca}^{2+}$ substitutions, may not only shift but also broaden the bands. 
Here, it can be noted that the assignment of the major bands observed on well-characterized pure or chemically doped synthetic samples appears to be quite robust in terms of frequency and polarization properties. This supports the strategy used to build the defect models, which is based on simple crystal-chemical considerations. However, it is not possible to fully rule out that other missing configurations or defects occur in natural samples. In this respect, the interplay between the occurrence of partial solid solutions, the presence of trace elements and the incorporation of $\mathrm{OH}$ groups cannot be tackled using only quantum-mechanical models which are intrinsically size-limited. In the same line, it could be hazardous to directly extrapolate the present results to pyroxenes with more complex chemical compositions, such as augite (Skogby, 2006) or omphacite (Koch-Müller et al., 2004; Katayama et al., 2006). These systems would deserve additional experimental and theoretical work, among which are low-temperature infrared spectroscopic measurements on experimental samples and advanced theoretical modelings enabling a more efficient sampling of the configurational space in large systems. 


\section{Appendix A}

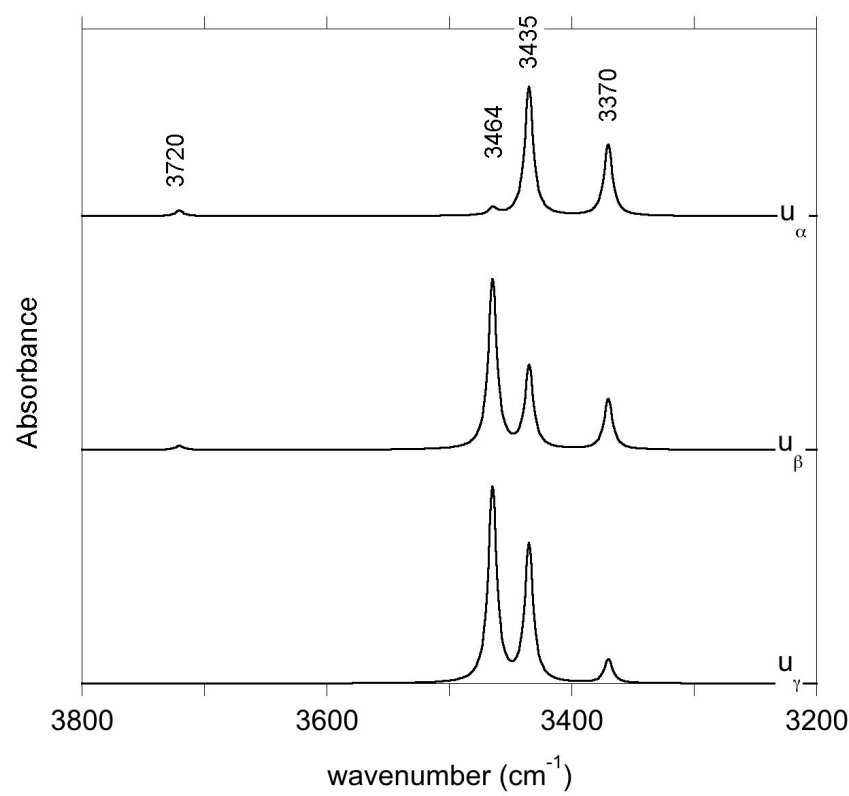

Figure A1. Theoretical infrared spectrum of the $(4 \mathrm{H}){ }_{\mathrm{Si}}^{\times}$defect.

\section{Appendix B: Properties of $\left[\left(2 \mathrm{H}^{+}\right)_{\mathrm{Si}}\left(\mathrm{Ti}^{4+}\right)_{\mathrm{M} 1}\right]^{\mathrm{X}}$ defects}

Here we investigate the various possible configurations of diopside defects with the $\left[\left(2 \mathrm{H}^{+}\right)_{\mathrm{Si}}\left(\mathrm{Ti}^{4+}\right)_{\mathrm{M} 1}\right]^{\times}$stoichiometry, i.e., doubly protonated vacancies with nearby $\mathrm{Ti}^{4+}$ for $\mathrm{Mg}^{2+}$ substitutions. The tetrahedral coordination of the $\mathrm{Si}$ atom corresponds to one $\mathrm{O} 1$, one $\mathrm{O} 2$ and two $\mathrm{O} 3$ atoms. Experimental $\mathrm{Si}-\mathrm{O}$ distances are $1.609(\mathrm{Si}-\mathrm{O} 1), 1.585(\mathrm{Si}-$ O2), and 1.665 and $1.687 \AA$ for O3_a and O3_b, respectively (Cameron et al., 1973). Accordingly, the doubly protonated vacancy can display two among four, i.e., six, different schemes of proton fixation. In addition, the $\mathrm{O} 1$ and $\mathrm{O} 2$ atoms are coordinated to two and one $\mathrm{Mg}$ atoms, respectively. The $\mathrm{O} 3$ atom is not coordinated to $\mathrm{Mg}$. In the following, the $\mathrm{Mg}$ atom linked to $\mathrm{O} 2$ is labeled $\mathrm{A}$, while the $\mathrm{Mg}$ atoms at a distance of 2.061 and $2.137 \AA$ of the $\mathrm{O} 1$ atom are labeled $\mathrm{B}$ and $\mathrm{C}$, respectively. Assuming that $\mathrm{O}$ atoms cannot be simultaneously coordinated by an $\mathrm{H}^{+}$and a $\mathrm{Ti}^{4+}$ ion, nine configurations of the defect can potentially occur, among which one $\left(\mathrm{O} 1, \mathrm{O} 3 \_\mathrm{a}, \mathrm{A}\right)$ is significantly more stable than the others (Table B1). Note that the "O3_a, O3_b, A" configuration was not found to be stable, and the $\mathrm{H}$ atom migrates from $\mathrm{O} 3 \mathrm{~b}$ to $\mathrm{O} 1$ leading to the "O1, O3_a, A" geometry.
Table B1. Properties of $\left[\left(2 \mathrm{H}^{+}\right)_{\mathrm{Si}}\left(\mathrm{Ti}^{4+}\right)_{\mathrm{M} 1}\right]^{\times}$defects.

\begin{tabular}{llrr}
\hline Configuration & $\begin{array}{l}\text { Rel. energy } \\
\left(\mathrm{kJ} \mathrm{mol}^{-1}\right)\end{array}$ & $\begin{array}{r}d_{\mathrm{OH}} \\
(\AA)\end{array}$ & $\begin{array}{r}\omega_{\mathrm{OH}} \\
\left(\mathrm{cm}^{-1}\right)\end{array}$ \\
\hline O2, O3_b, B & 19.8 & $0.976,0.987$ & 3542,3363 \\
O2, O3_a, B & 43.5 & $0.966,0.987$ & 3726,3341 \\
O2, O3_b, C & 35.9 & $0.979,0.997$ & 3498,3181 \\
O2, O3_a, C & 34.0 & $0.967,0.995$ & 3735,3188 \\
O1, O3_a, A & 0.0 & $0.980,0.985$ & 3494,3352 \\
O1, O3_b, A & 19.9 & $0.997,0.998$ & 3221,3110 \\
O3_a, O3_b, A & Not stable & - & - \\
O3_a, O3_b, B & 19.8 & $0.976,0.987$ & 3533,3361 \\
O3_a, O3_b, C & 35.8 & $0.979,0.997$ & 3492,3178 \\
\hline
\end{tabular}

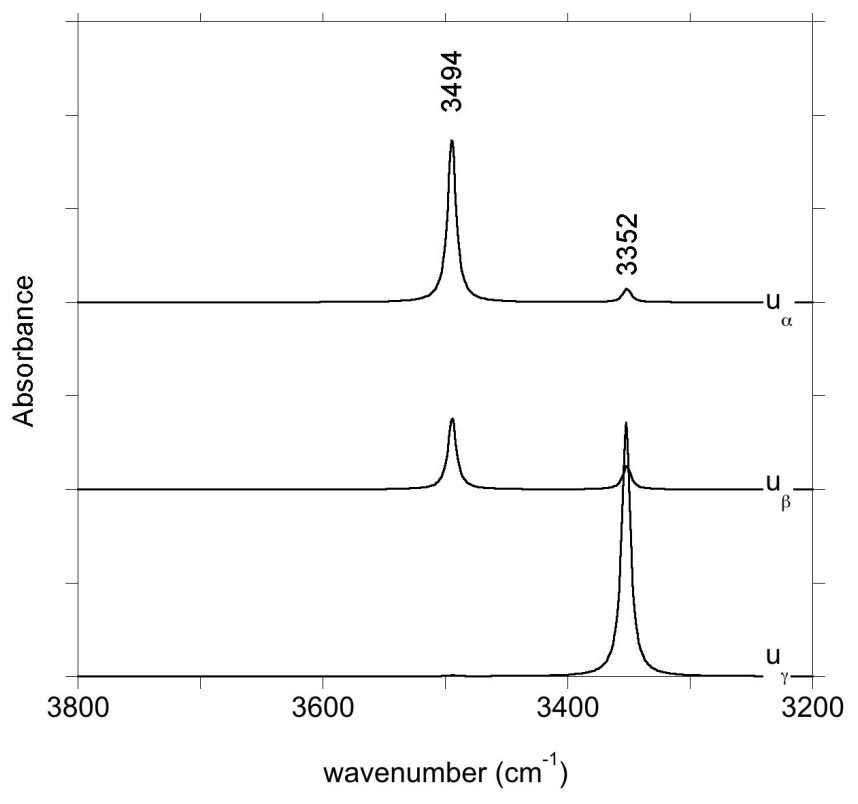

Figure B1. Theoretical infrared spectrum of the $\left[\left(2 \mathrm{H}^{+}\right)_{\mathrm{Si}}\left(\mathrm{Ti}^{4+}\right)_{\mathrm{M} 1}\right]^{\times} \operatorname{defect}$ (configuration O1, O3_a, A). 
Code and data availability. Structure drawings have been produced with the Vesta software (Momma and Izumi, 2011). PWscf and PHonon codes (Giannozzi et al., 2009) are available at http: //www.quantum-espresso.org/ (last access: 1 October 2020). Model structures are provided as Supplement files in ".vesta" and ".cif" formats.

Supplement. The supplement related to this article is available online at: https://doi.org/10.5194/ejm-32-505-2020-supplement.

Author contributions. JI and EB designed the study. JL and JI performed the FTIR measurements. EB and LP performed the simulations. All coauthors discussed the results and prepared the paper.

Competing interests. The authors declare that they have no conflict of interest.

Acknowledgements. Reviews by Jörg Hermann and the one anonymous reviewer are acknowledged with appreciation. Louis d'Hendecourt is acknowledged for providing access to the cryogenic FTIR equipment at IAS, Orsay.

Financial support. Calculations have been performed using the computing resources of IMPMC (Sorbonne Université-CNRS$\mathrm{MNHN}$ ) and the HPC resources of IDRIS under the allocation 2020-A0080910820 attributed to GENCI (Grand Equipement National de Calcul Intensif). This work was supported by the TelluS Program of CNRS-INSU.

Review statement. This paper was edited by Reto Gieré and reviewed by Jörg Hermann and one anonymous referee.

\section{References}

Andrut, M., Brandstätter, F., and Beran, A.: Trace hydrogen zoning in diopside, Miner. Petrol., 78, 231-241, https://doi.org/10.1007/s00710-002-0226-z, 2003.

Andrut, M., Wildner, M., Ingrin, J., and Beran, A.: Mechanisms of $\mathrm{OH}$ defect incorporation in naturally occurring, hydrothermally formed diopside and jadeite, Phys. Chem. Miner., 34, 543-549, https://doi.org/10.1007/s00269-007-0169-3, 2007.

Azevedo-Vannson, S., France, L., Ingrin, J., and Chazot, G.: Mantle metasomatism influence on water contents in continental lithosphere: new constraints from garnet pyroxenite xenoliths (France \& Cameroon volcanic provinces), Lithos, in review, 2020.

Balan, E., Refson, K., Blanchard, M., Delattre, S., Lazzeri, M., Ingrin, J., Mauri, F., Wright, K., and Winkler, B.: Theoretical infrared absorption coefficient of $\mathrm{OH}$ groups in minerals, Am. Mineral., 93, 950-953, https://doi.org/10.2138/am.2008.2889, 2008.

Balan, E., Ingrin, J., Delattre, S., Kovacs, I., and Blanchard, M.: Theoretical infrared spectrum of $\mathrm{OH}-$ defects in forsterite,
Eur. J. Mineral., 23, 285-292, https://doi.org/10.1127/09351221/2011/0023-2090, 2011.

Balan, E., Blanchard, M., Yi, H., and Ingrin, J.: Theoretical study of $\mathrm{OH}$-defects in pure enstatite, Phys. Chem. Miner. 40, 41-50, https://doi.org/10.1007/s00269-012-0544-6, 2012.

Balan, E., Yi, H., and Blanchard, M.: First principles study of $\mathrm{OH}$ defects in zircon, Phys. Chem. Miner., 7, 547-554, https://doi.org/10.1007/s00269-013-0591-7, 2013.

Balan, E., Blanchard, M., Lazzeri, M., and Ingrin, J.: Theoretical Raman spectrum and anharmonicity of tetrahedral $\mathrm{OH}$ defects in hydrous forsterite, Eur. J. Mineral., 29, 201-212, https://doi.org/10.1127/ejm/2017/0029-2599, 2017.

Balan, E., Créon, L., Sanloup, C., Aléon, J., Blanchard, M., Paulatto, L., and Bureau, H.: First-principles modeling of chlorine isotope fractionation between chloridebearing molecules and minerals, Chem. Geol., 525, 424-434, https://doi.org/10.1016/j.chemgeo.2019.07.032, 2019.

Balan, E.: Theoretical infrared spectra of $\mathrm{OH}$ defects in corundum $\left(\alpha-\mathrm{Al}_{2} \mathrm{O}_{3}\right)$, Eur. J. Mineral., 32, 457-467, https://doi.org/10.5194/ejm-32-457-2020, 2020.

Baroni, S., de Gironcoli, S., Dal Corso, A., and Giannozzi, P.: Phonons and related crystal properties from densityfunctional perturbation theory, Rev. Mod. Phys., 73, 515-561, https://doi.org/10.1103/RevModPhys.73.515, 2001.

Bell, D. R., Ihinger, P. D., and Rossman, G. R.: Quantitative analysis of trace $\mathrm{OH}$ in garnet and pyroxenes, Am. Mineral., 80, 465-474, 1995.

Beran, A.: Messung des Ultrarot-Pleochroismus von Mineralen. XIV. Der pleochroismus der OH-streckfrequenz in diopsid, Tscher. Miner. Petrog., 23, 79-85, https://doi.org/10.1007/BF01081476, 1976.

Berry, A. J., Hermann, J., O’Neill, H. S. C., and Foran, G. J.: Fingerprinting the water site in mantle olivine, Geology, 33, 869-872, https://doi.org/10.1130/G21759.1, 2005.

Blanchard, M., Balan, E., and Wright, K.: Incorporation of water in iron-free ringwoodite : a first-principles study, Am. Mineral., 94, 83-89, https://doi.org/10.2138/am.2009.3020, 2009.

Blanchard, M., Ingrin, J., Balan, E., Kovács, I., and Withers, A. C.: Effect of iron and trivalent cations on $\mathrm{OH}$-defects in olivine, Am. Mineral., 102, 302-311, https://doi.org/10.2138/am-2017-5777, 2017.

Bromiley, G. D., Keppler, H., McCammon, C. A., Bromiley, F. A., and Jacobsen, S. D.: Hydrogen solubility and speciation in natural, gem-quality chromian diopside, Am. Mineral., 89, 941-949, https://doi.org/10.2138/am-2004-0703, 2004.

Cameron, M., Shigeho, S., Prewitt, C. T., and Papike, J. J.: Hightemperature crystal chemistry of acmite, diopside, hedenbergite, jadeite, spodumene and ureyite, Am. Mineral., 58, 594-618, 1973.

Deer, W. A., Howie, R. A., and Zussman J.: Rock-forming minerals, 2nd Edn., v. 2A, single-chain silicates, Geological Society London, 1978.

Demouchy, S. and Bolfan-Casanova, N.: Distribution and transport of hydrogen in the lithospheric mantle: A review, Lithos, 240-243, 402-425, https://doi.org/10.1016/j.lithos.2015.11.012, 2016.

Denis, C. M. M., Alard, O., and Demouchy, S.: Water content and hydrogen behaviour during metasomatism in the uppermost mantle beneath Ray Pic volcano (Massif Central, France), Lithos, 
236-237, 256-274, https://doi.org/10.1016/j.lithos.2015.08.013, 2015.

Gatzemeier, A. and Wright, K.: Computer modelling of hydrogen defects in the clinopyroxenes diopside and jadeite, Phys. Chem. Miner., 33, 115-125, 2006.

Gavrilenko, P., Boffa-Ballaran, T., and Keppler, H.: The effect of A1 and water on the compressibility of diopside, Am. Mineral., 95, 608-616, https://doi.org/10.2138/am.2010.3400, 2010.

Geiger, C. A. and Rossman, G. R.: IR spectroscopy and $\mathrm{OH}^{-}$in silicate garnet: The long quest to document the hydrogarnet substitution, Am. Mineral., 103, 384-393, https://doi.org/10.2138/am2018-6160CCBY, 2018.

Giannozzi, P., Baroni, S., Bonini, N., Calandra, M., Car, R., Cavazzoni, C., Ceresoli, D., Chiarotti, G. L., Cococcioni, M., Dabo, I., Dal Corso, A., de Gironcoli, S., Fabris, S., Fratesi, G., Gebauer, R., Gerstmann, U., Gougoussis, C., Kokalj, A., Lazzeri, M., Martin-Samos, L., Marzari, N., Mauri, F., Mazzarello, R., Paolini, S., Pasquarello, A., Paulatto, L., Sbraccia, C., Scandolo, S., Sclauzero, G., Seitsonen, A. P., Smogunov, A., Umari, P., and Wentzcovitch, R. M.: Quantum ESPRESSO: a modular and open-source software project for quantum simulations of materials, J. Phys. Cond. Mat., 21, 395502, https://doi.org/10.1088/0953-8984/21/39/395502, 2009.

Hamann, D. R.: Optimized norm-conserving Vanderbilt pseudopotentials, Phys. Rev. B, 88, 085117, https://doi.org/10.1103/PhysRevB.88.085117, 2013.

Hess, H. H.: Chemical composition and optical properties of common clinopyroxene, Am. Mineral., 34, 621-666, 1949.

Ingrin, J., Latrous, K., Doukhan, J.-C., and Doukhan, N.: Water in diopside: an electron microscopy and infrared study, Eur. J. Mineral., 1, 327-341, https://doi.org/10.1127/ejm/1/3/0327, 1989.

Ingrin, J., Liu, J., Depecker, C., Kohn, S. C., Balan, E., and Grant, K. J.: Low-temperature evolution of $\mathrm{OH}$ bands in synthetic forsterite, implication for the nature of $\mathrm{H}$ defects at high pressure, Phys. Chem. Miner., 40, 499-510, https://doi.org/10.1007/s00269-013-0587-3, 2013.

Ingrin, J., Kovács, I., Deloule, E., Balan, E., Blanchard, M., Kohn, S. C., and Hermann, J.: Identification of hydrogen defects linked to boron substitution in synthetic forsterite and natural olivine, Am. Mineral., 99, 2138-2141, https://doi.org/10.2138/am-20145049, 2014.

Johnson, E. A., Rossman, G. R., Dyar, M. D., and Valley, J. W.: Correlation between $\mathrm{OH}$ concentration and oxygen isotope diffusion rate in diopsides from the Adirondack Mountains, New York, Am. Mineral., 87, 899-908, https://doi.org/10.2138/am2002-0713, 2002.

Jollands, M. C., Blanchard, M., and Balan, E.: Structure and theoretical infrared spectra of $\mathrm{OH}$ defects in quartz, Eur. J. Mineral., 32, 311-323, https://doi.org/10.5194/ejm-32-311-2020, 2020.

Katayama, I., Nakashima, S., and Yurimoto, H.: Water content in natural eclogite and implication for water transport into the deep upper mantle. Lithos, 86, 245-259, 2006.

Keppler, H. and Smyth, J. R. (Eds.): Water in nominally anhydrous minerals, The Mineralogical Society of America, Chantilly, Virginia, Rev. Mineral. Geochem., 62, 478 pp., ISBN 0-939950-74X, ISBN13 978-0-939950-74-4, 2006.

Koch-Müller, M., Matsyuk, S. S., and Wirth, R.: Hydroxyl in omphacites and omphacitic clinopyroxenes of upper mantle to lower crustal origin beneath the Siberian platform, Am. Mineral., 89, 921-931, 2004.

Kovács, I., O’Neill, H. St .C., Hermann, J., and Hauri, E. H.: Sitespecific infrared $\mathrm{OH}$ absorption coefficients for water substitution into olivine, Am. Mineral., 95, 292-299, 2010.

Lemaire, C., Kohn, S. C., and Brooker, R. A.: The effect of silica activity on the incorporation mechanisms of water in synthetic forsterite: a polarised infrared spectroscopic study, Contrib. Mineral. Petr., 147, 48-57, https://doi.org/10.1007/s00410003-0539-x, 2004.

Libowitzky, E.: Correlation of $\mathrm{O}-\mathrm{H}$ stretching frequencies and $\mathrm{O}$ $\mathrm{H}$...O hydrogen bond lengths in minerals, Monatsh. Chemie, 130, 1047-1059, https://doi.org/10.1007/BF03354882, 1999.

Libowitzky, E. and Beran, A.: The structure of hydrous species in nominally anhydrous minerals: Information from polarized IR spectroscopy, Rev. Mineral. Geochem., 62, 29-52, 2006.

Momma, K. and Izumi, F.: VESTA 3 for three-dimensional visualization of crystal, volumetric and morphology data, J. Appl. Crystallogr., 44, 1272-1276, https://doi.org/10.1107/S0021889811038970, 2011.

Nasdala, L., Beran, A., Libowitzky, E., and Wolf, D.: The incorporation of hydroxyl groups and molecular water in natural zircon $\left(\mathrm{ZrSiO}_{4}\right)$, Am. J. Sci., 301, 831-857, https://doi.org/10.2475/ajs.301.10.831, 2001.

Nobes, R. H, Akhmatskaya, E. V., Milman, V., White, J. A., Winkler, B., and Pickard, C. J.: An ab initio study of hydrogarnets, Am. Mineral., 85, 1706-1715, https://doi.org/10.2138/am-200011-1214, 2000.

Patkó, L., Liptai, N., Kovács, I. J., Aradi, L. E., Xia, Q.-K., Ingrin, J., Mihaily, J., O’Reilly, S. Y., Griffin, W. L., Wesztergom, V., and Szabó, C.: Extremely low structural hydroxyl contents in upper mantle xenoliths from the Noìgraìd-Gomor Volcanic Field (northern Pannonian Basin): Geodynamic implications and the role of post-eruptive re-equilibration, Chem. Geol., 507, 23-41, https://doi.org/10.1016/j.chemgeo.2018.12.017, 2019.

Perdew, J. P., Burke, K., and Ernzerhof, M.: Generalized Gradient Approximation Made Simple, Phys. Rev. Lett., 77, 3865-3868, https://doi.org/10.1103/PhysRevLett.77.3865, 1996.

Purwin, H., Stalder, R., and Skogby, H.: Hydrogen incorporation in Fe- and Na-doped diopsides, Eur. J. Mineral., 21, 691-704, https://doi.org/10.1127/0935-1221/2009/0021-1938, 2009.

Quartieri, S., Antonioli, G., Artioli, G., and Lottici, P. P.: XANES study of titanium coordination in natural diopsidic pyroxenes, Eur. J. Mineral., 5, 1101-1109, https://doi.org/10.1127/ejm/5/6/1101, 1993.

Reynes, J., Lanari, P., and Hermann, J.: A mapping approach for the investigation of $\mathrm{Ti}-\mathrm{OH}$ relationships in metamorphic garnet, Contrib. Mineral. Petr., 175, 46, https://doi.org/10.1007/s00410020-01681-5, 2020.

Sambridge, M., Gerald, J. F., Kovacs, I., O’Neill, H. S. C., and Hermann, J.: Quantitative absorbance spectroscopy with unpolarized light: Part I. Physical and mathematical development, Am. Mineral. 93, 751-764, https://doi.org/10.2138/am.2008.2657, 2008.

Schlipf, M. and Gygi, F.: Optimization algorithm for the generation of ONCV pseudopotentials, Comput. Phys. Comm., 196, 36-44, https://doi.org/10.1016/j.cpc.2015.05.011, 2015.

Shuai K. and Yang X.: Quantitative analysis of H-species in anisotropic minerals by polarized infrared spectroscopy along 
three orthogonal directions, Contrib. Mineral. Petr., 172, 14, https://doi.org/10.1007/s00410-017-1336-2, 2017.

Skogby, H.: OH incorporation in synthetic clinopyroxene, Am. Mineral., 79, 240-249, 1994.

Skogby, H.: Water in natural mantle minerals I: Pyroxenes, Rev. Mineral. Geochem., 62, 155-167, 2006.

Skogby, H., Bell, D. R., and Rossman, G. R.: Hydroxide in pyroxene: variations in the natural environment, Am. Mineral., 75, 764-774, 1990.

Stalder, R. and Ludwig, T.: $\mathrm{OH}$ incorporation in synthetic diopside, Eur. J. Mineral., 19, 373-380, https://doi.org/10.1127/09351221/2007/0019-1721, 2007.

Stalder, R., Prechtel, F., and Ludwig, T..: No site-specific infrared absorption coefficient for $\mathrm{OH}$-defects in pure enstatite, Eur. J. Mineral., 24, 465-470, https://doi.org/10.1127/09351221/2012/0024-2180, 2012.
Sundvall, R., Skogby, H., and Stalder, R.: Hydrogen diffusion in synthetic Fe-free diopside, Eur. J. Mineral., 21, 963-970, https://doi.org/10.1127/0935-1221/2009/0021-1971, 2009.

Walker, A. M., Hermann, J., Berry, A. J., and O'Neill, H. St. C.: Three water sites in upper mantle olivine and the role of titanium in the water weakening mechanism, J. Geophys. Res., 112, B05211, https://doi.org/10.1029/2006JB004620, 2007.

Wright, K.: Atomistic models of $\mathrm{OH}$ defects in nominally anhydrous minerals, Rev. Mineral. Geochem., 62, 67-83, 2006.

Yang, Y., Ingrin, J., Xia, Q., and Liu, W.: Nature of hydrogen defects in clinopyroxenes from room temperature up to $1000^{\circ} \mathrm{C}$ : Implication for the preservation of hydrogen in the upper mantle and impact on electrical conductivity, Am. Mineral., 104, 79-93, https://doi.org/10.2138/am-2019-6661, 2019. 